\title{
Do markets make good commissioners?: A quasi-experimental analysis of retail electric restructuring in Ohio
}

\author{
Noah Dormady ${ }^{1 *}$, Zhongnan Jiang $^{1}$ and Matthew Hoyt ${ }^{2}$ \\ ${ }^{1}$ John Glenn College of Public Affairs, The Ohio State University, USA and ${ }^{2}$ Exeter Associates, USA \\ ${ }^{*}$ Corresponding author. Email: dormady.1@osu.edu
}

(Received 2 June 2017; revised 12 April 2018; accepted 16 April 2018;

first published online 3 July 2018)

\begin{abstract}
Empirical support for the purported benefits of retail electric deregulation is mixed at best. Prior studies that identify states as simply "retail deregulated" overlook complex policy environments in which deregulation is implemented by regulators with a high degree of discretion. Prior studies also rely on Energy Information Administration data that do not account for core regulatory interventions that can take place during the process of implementing deregulation. Using robust time series household final bill survey data from the Public Utilities Commission of Ohio, this article provides a quasi-experimental analysis of the price impacts of retail electric restructuring in Ohio. The results suggest that residential electricity prices have increased following retail restructuring in all service territories in Ohio, with significant favourable welfare effects observed only in the Cincinnati area, where key policy implementation stages were not circumvented.
\end{abstract}

Keywords deregulation; public utilities; policy implementation; quasi-experiments

\section{Introduction}

The promise of electric deregulation has long eluded dinner-table conversation in the American household. However, although it is uncommon discussion fodder for residential consumers at home, electric deregulation policy is much debated by legislators and regulators. This is partly because of its potentially significant impact on consumer welfare through the effect it has on the monthly bills customers pay and the essential nature of electricity service in the modern economy. Given its importance to consumers and a recent resurgence in legislative attention to the subject, identified below, the study of the implementation and effect of electric deregulation is of renewed interest to scholars. Deregulation's "promise" was increased efficiency and decreased retail rates to both households and businesses through the introduction of competition (Winston 1993; Newbery 1999; Hunt 2002). These benefits have not been consistently identified in the literature evaluating deregulation of electric markets. This article provides an empirical analysis 
of the State of Ohio's experience with retail electric deregulation. The unique context allows us to evaluate both the underlying theory and its implementation. We find that the divergence between the promise of deregulation and what consumers have actually observed may be less of a flaw in the underlying deregulatory theory than problems with the implementation of deregulatory policy.

The underlying theory of electric market deregulation, also known as restructuring, is based upon a long-standing literature that argues that liberalising the industry can reform some of the well-understood distortions of public utility regulation (Stigler and Friedland 1962; Joskow and Schmalensee 1983; Peltzman 1989; Phillips 1993). A subsequent reform agenda was pursued predominantly at a wholesale level, affecting the generation and transmission of electricity and leading to the creation of restructured wholesale energy markets. Despite pushing for these changes, scholars argued that regulators should still play a fundamental role in overseeing fair and efficient retail rates for regional distribution utilities, and that deregulation should not eliminate regulatory rate-setting at the retail level (Joskow and Schmalensee 1983; Hilke 2008). The "textbook" model of electric restructuring called for retail deregulation only after extensive and careful market development, as well as the functional separation of competitive and noncompetitive services (Hunt 2002; Joskow 2005a, 2008).

In practice, retail deregulation, or "retail choice" as it is often called, means that residential customers can either "shop" from among competing marketers to supply their generation on a contractual basis ${ }^{1}$ or remain with the regional monopoly supplier and be charged a rate that is set by some competitive processes, such as a supply auction, detailed below. Full retail deregulation effectively divorces commission oversight from setting electric rates for everything except local distribution service. Although most states today that deregulated have done so in wholesale markets, an increasing number are fully, or at least partially, liberalising retail electricity service as well. ${ }^{2}$

While it is tempting to simplify the issue by identifying states as either "regulated" or "deregulated", we caution against this oversimplification. Ultimately, electric deregulation exists on a continuum that varies by the degree of commission involvement in rate-setting. Many states that introduced competition into their electricity markets still maintain some level of commission oversight, and thus prudence review, over the behaviours of regional monopoly distribution utilities. Consequently, the effect that households observe is fundamentally a product of how this underlying theory is implemented.

Today, there is a lack of definitive empirical evidence regarding how electricity restructuring has ultimately affected the welfare of businesses and households (Eto et al. 2006; Joskow 2008; Kwoka 2008). Moreover, prior evaluations of electric restructuring's impacts focused almost exclusively on wholesale market dynamics, such as generation efficiencies (Markiewicz et al. 2004; Bushnell and Wolfram 2005; Craig and Savage 2013; Cicala 2014) and wholesale prices (Green and Newbery 1992; Chapman et al. 2004; Puller 2007; Hortaçsu and Puller 2008; Mansur 2008; Davis and Wolfram 2012; Dias and Ramos 2014). The body of scholarship that does

\footnotetext{
${ }^{1}$ This is often referred to as "switching" from the retail monopoly provider.

${ }^{2}$ The following states have adopted various forms of liberalised electric choice markets: TX, IL, OH, PA, MD, NY, CT, RI, DE, ME, NH and MA. Partial or capped electric choice exists in CA, MI, MT, VA, AZ, OR, MT and NV (DNV-GL 2015).
} 
study the effect of retail restructuring on consumer rates is growing, but remains incomplete and is often contradictory. Apt (2005), using a diff-in-diff approach and looking at the rate of change in industrial prices, found that restructuring did not lead to lower prices. Fagan (2006), in contrast, found that industrial prices in restructured states outperformed predicted prices using a counterfactual model. Swadley and Yücel (2011) similarly found, using a dynamic panel model, that retail competition led to lower prices. Taber et al. (2006) tested a variety of model specifications and deregulation definitions and observed that consumers in deregulated states faced higher relative prices. Their research, however, did not account for retail choice. Joskow's (2006) econometric study of electric restructuring identified between a 5 and $10 \%$ decrease in real retail prices owing to both wholesale and retail restructuring. This work, however, is also limited by problems stemming from the extent of restructuring and measurements of electric prices.

The handful of more recent studies on the price effects of restructuring do not resolve the contradictions identified in the first wave of restructuring studies. $\mathrm{Su}$ (2015) found that retail competition led to mixed-to-lower prices, with benefits mainly seen by residential customers. Ros (2017) also identified lower prices, but found the greatest and most sustained savings accruing to industrial customers with the least benefit flowing to the residential class. Intra- and interstate variation in price effects is attributed in some studies to fuel prices as mediated by utility fuel mix, although this relationship depends on the extent that restructuring mechanisms allowed greater pass-through of wholesale market costs to consumers (Borenstein and Bushnell 2015). Although the bulk of the literature studying deregulation policy and its impact is concentrated in the 2000s, the impact of electricity market restructuring is again salient to policymakers. Several restructured states are considering reregulating energy services or introducing greater regulatory oversight to shield preferred generation resources against market forces. ${ }^{3}$ In addition, in the intervening years since the initial studies, many markets previously considered to be "deregulated" finally implemented or completed major restructuring reforms for the first time.

The State of Ohio offers a robust opportunity for evaluating the effects of retail restructuring, as well as the relationship between these effects and policy implementation. Ohio is technically deregulated in both the wholesale and retail markets; however, important regulatory vestiges remain that have affected prices in key ways. Like many similar states, Ohio's implementation diverged from the core textbook model of deregulation in two important ways. First, the statutory language is ambiguous on a key deregulatory design feature. Statutory ambiguity has been identified as a cause of implementation failure (Sabatier and Mazmanian 1980; Mazmanian and Sabatier 1981; Huber and Shipan 2002; Hill, 2003; Zahariadis and Exadaktylos 2016). It gives agencies wide latitude in implementing statutes (Mahoney and Thelen 2010). The statutory language called only for corporate, rather than functional, separation of generation from distribution. In other words, rather than requiring utilities to divest their competitive generation assets (almost entirely legacy coal plants), the commission used their broad discretion to allow utilities to create arms-length, affiliate corporations, which retained ownership of generation assets.

\footnotetext{
${ }^{3}$ For example, legislators are proposing "Zero Emission Credits" in Illinois and New York to provide additional support to nuclear facilities that are struggling to remain solvent owing to pressure from competitive markets.
} 
Second, the statute allowed the commission to structure decision rules that permitted rent-seeking (Krueger 1974; Wright 1977; Appelbaum and Katz 1987; Tullock 2001; Carter et al. 2015). The commission pursued a distribution ratesetting process that eased the procedural requirements for adding nonbypassable riders and surcharges to customers' bills. This permitted utilities to broadly pursue cost recovery, including for their arms-length deregulated plants. The textbook model of deregulation calls for deregulated plants to recover their costs solely through the wholesale market so that customer welfare is not tied to the fortunes of a regional monopoly utility without regulatory protection. Ohio's context uniquely allows us to compare the policy and its implementation, as one of the state's four utilities (Duke Energy) followed a more textbook model of retail deregulation by functionally divesting its generation assets. It thus had no instrumental interest to recover generation-related costs by adding riders to electric bills.

The case of Ohio also uniquely allows us to assess retail restructuring because the state maintains accurate residential final bill data that provide far more detailed information than the data source typically used in competing studies - Energy Information Administration (EIA) data. EIA data do not include revenues obtained through riders and surcharges. In addition, the transition towards market-based retail rates and more limited commission rate-setting was sudden, allowing for a robust quasi-experimental evaluation with a clean cut/intervention point to provide for a pre- and post-assessment.

We begin by providing a concise case history of electric restructuring in Ohio to provide both context for our empirical work and to elucidate the specific market design and implementation path pursued. We then describe the data we utilise and general trends in the costs customers have faced. From this, we provide the results of quasi-experimental analyses for the seven largest indicative metro areas, or service territories, in Ohio, representing the majority of the state and excluding only rural coops, municipal power and municipal aggregators. ${ }^{4}$ We provide estimates of the impacts of retail market restructuring on residential electricity bills. We also provide welfare impact estimates for these territories. We conclude with insights for the current reregulation debate, and policy implementation more broadly.

\section{The case of restructuring in Ohio}

Before restructuring, Ohio's predominant electric utility model relied on vertically integrated monopolies. These monopolies oversaw all aspects of electricity provision: generation, transmission and distribution (T\&D) and retail services. These utilities were overseen by the Public Utilities Commission of Ohio (PUCO) and subject to price and cost regulation, consisting of the cost of operation plus a return on "used and useful" capital investment (Shapiro and Tomain 2003). Four investor-owned utilities (IOUs) - FirstEnergy, American Electric Power (AEP), Duke Energy and Dayton Power \& Light (DP\&L) - provided nearly $90 \%$ of electric market services in $1999 .^{5}$

${ }^{4}$ Ohio allows municipal governments to enter into retail energy contracts on behalf of unswitched residents after ballot approval via "aggregation." See Littlechild (2008) for a more thorough discussion of this policy in Ohio.

${ }^{5}$ FirstEnergy is inclusive of Toledo Edison, Ohio Edison and Cleveland Electric Illuminating Co. AEP is inclusive of Ohio Power Co. and Columbus Southern Power (CSP) Co. CSP merged into Ohio Power in 2012. Duke Energy acquired Cinergy Corp., the successor of Cincinnati Gas \& Electric Co., in 2006. 
Under regulation, PUCO attempted to balance consumer and utility interests through traditional ratemaking proceedings, including systematic review of rate components.

Ohio, like many peer states, faced a political climate favourable to electric restructuring in the 1990s, particularly at a wholesale market level. At this time, low natural gas prices relative to alternative fuels contributed to low marginal costs in liberalised wholesale markets. The Federal Energy Regulatory Commission (FERC) put forth rules for nondiscriminatory access to wholesale power markets with FERC Order 888 in 1996, essentially opening up these markets. This order installed independent system operators (ISOs), run by impartial dispatchers, to oversee the flow of generated electricity across transmission networks, as opposed to local utilities (Hogan 1998; Hunt 2002; Joskow 2005b; Pollitt 2012). FERC later refined the ISO concept with FERC Order 2000 in 1999, tasking newly created regional transmission organisations (RTOs) to manage wholesale market design and administration (Chandley 2001; Hunt 2002; Joskow 2005b).

As an added incentive to reform, Ohio utilities charged customers high average costs under the traditional monopoly system. Although the average utility retail price of 9.09 cents/kWh (2014 dollars) ${ }^{6}$ in 1999 was only 22 nd highest out of the 50 United States' states, Ohio's electric consumption, led by a large industrial sector, was the fourth highest in the country (EIA 2001). Given the prospect of accessing cheaper wholesale electricity, some industrial and commercial interest groups intensely lobbied in support of wholesale restructuring. Proponents argued that deregulation would lead to welfare gains for all involved parties.

Ohio initiated its effort to deregulate by passing Senate Bill (SB) 3 in June 1999. One of the stated goals of SB 3 was to reduce costs and increase choice for all customers. Consequently, SB 3 established a path towards retail restructuring in addition to wholesale reforms. A timeline of major events in the history of Ohio electric restructuring starting with SB 3 is included in Figure 1, and specific dates are listed in Appendix Table A.1. SB 3 established 1 January 2001 as the starting date of competitive retail electric service and unbundled electric services to allow customers the ability to "shop" for a retailer of choice, known as competitive retail electric suppliers (CRES). ${ }^{7}$ SB 3 also established a five-year Market Development Period during which time incumbent utilities could collect market transition revenues (i.e. stranded costs) either through a rate freeze with specified adjustments or transition charges paid by customers who switched supply [Ohio Legislative Service Commission (OLSC) 1999].

A law declaring the existence of a market does not necessarily mean that the market will materialise. In Ohio's case, instead of first developing an adequate retail market, the restructuring process started with efforts to subsidise switching. ${ }^{8}$ This approach was ill-advised, as switching incentives had no basis in actual market

\footnotetext{
${ }^{6} 6.4$ cents/kWh in 1999 dollars. This amount can be further divided into average residential (8.68), commercial (7.67), industrial (4.33) and other (5.96) costs, all in terms of cents/kWh in 1999 dollars (EIA 2001). Conversion to 2014 dollars was made using CPI. These rates are bundled, meaning they are inclusive of both the generation and T\&D components of billed costs.

${ }^{7}$ Specifically, SB 3 declared "electricity generation service, aggregation service, power marketing and power brokering as competitive retail electric services" and conditionally authorised "ancillary service, metering service and billing and collection service to be declared competitive services" (OLSC 1999).

${ }^{8}$ The PUCO required a 5\% rate reduction for residential customers and tied transition revenue to IOU's ability to obtain a $20 \%$ customer switch rate during the development period. Utilities introduced switching incentives in response. For example, FirstEnergy made a limited supply of discounted generation available
} 
Timeline of Major Market Events in Ohio's Electric Restructuring

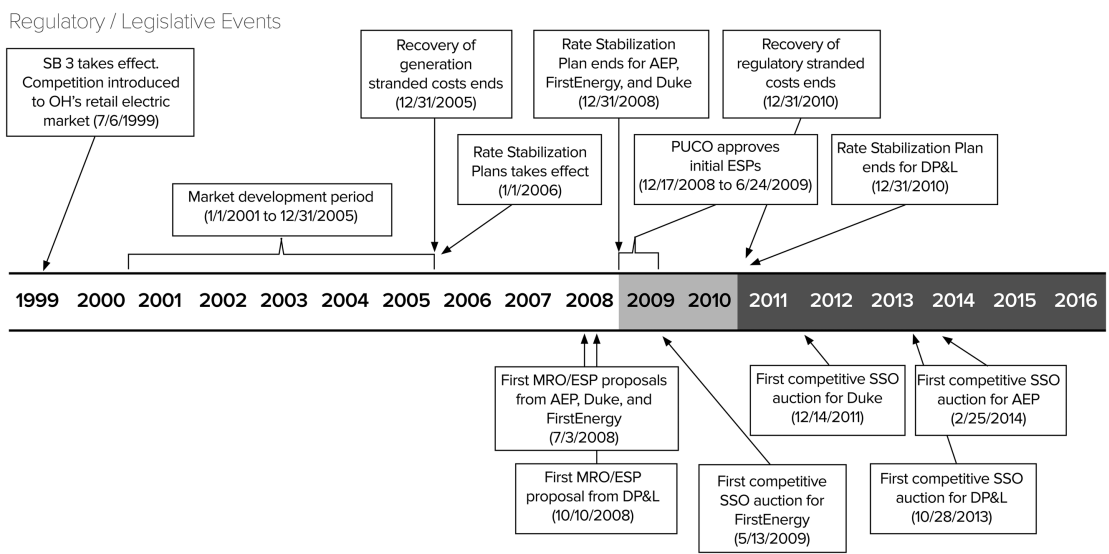

Figure 1. Timeline of major market events in Ohio's electric restructuring. Note: $\mathrm{SB}=$ Senate Bill; $\mathrm{AEP}=$ American Electric Power; $\mathrm{PUCO}=$ Public Utilities Commission of Ohio; ESP = Electric Security Plan; DP\&L = Dayton Power \& Light; MRO = Market Rate Offer; SSO = standard service offer.

Source: authors.

price, little progress had been made to reduce market concentration or create firewalls between regulated utilities and deregulated subsidiaries and few rules of conduct existed for CRES. These supply-side flaws caused issues related to market power, gaming and inefficiency that all deterred suppliers from participating in the retail market (Hunt 2002). Unsurprisingly, a competitive retail electric market did not develop as envisioned by the proponents of SB 3. ${ }^{9}$ The PUCO, observing this situation, adopted the rhetoric used by utilities that a clean change to market-based rates would lead to "rate "sticker shock"' (PUCO 2007). It is important to note that utilities had a financial interest in maintaining regulated rates as it allowed them to continue earning guaranteed, regulated returns on generation assets.

Instead of concluding market development, the PUCO opted to delay its end with the backing of the Ohio Legislature. Between October 2002 and January 2005, the PUCO approved individually negotiated Rate Stabilization Plans (RSPs) - a continuation of regulated ratemaking and elements of market development - with all four major Ohio IOUs. ${ }^{10}$ During this period, utilities sought additional returns as a means to further recover stranded costs before open wholesale market competition. Although the recovery of generation stranded costs statutorily ended 31 December 2005, RSPs allowed FirstEnergy, AEP, and Duke Energy to continue receiving regulated rates that included transition cost recovery until 31 December

to marketers, whereas Duke Energy created customer discount incentives only available to the initial customers to switch supplier (Littlechild 2008).

${ }^{9}$ During this time no actual customer switching occurred except for a small proportion of customers who engaged in municipal retail aggregation efforts in the Duke and FirstEnergy territories. The PUCO attributed this to volatile and rising market prices owing to slowing electricity demand, increasing input costs and the halting development of regional ISOs (NARUC 2013).

${ }^{10}$ All four agreements were largely upheld by the Ohio Supreme Court after challenges to the PUCO's decisions. Notably, FirstEnergy and AEP were required to submit proposals to establish competitive service options (PUCO 2007). 
2008, and DP\&L until 31 December 2010. ${ }^{11}$ These dates thus become the key policy intervention dates for our quasi-experimental estimation as these dates identify the end of comprehensive commission rate-setting.

Of critical importance to Ohio's restructuring process was the fact that SB 3, although it instructed incumbent utilities to unbundle, did not unambiguously specify a requirement for functional separation (i.e. divesture) of competitive assets, including generation. Rather, it required that utilities "corporately separate". By requiring each utility to develop a corporate separation plan, the statute was sufficiently ambiguous that the PUCO could permit utilities to technically unbundle by divesting their generation assets to an arms-length corporation owned by the same parent corporation. For example, the PUCO approved a corporate separation plan for AEP Ohio that allowed it to sell its generation (a legacy coal fleet) to the newly created AEP Generation Resources, LLC, owned by AEP Ohio's parent corporation. Similar arms-length firms were created by FirstEnergy and DP\&L.

The provisional status of Ohio's electric restructuring was clarified with the passage of SB 221 in May 2008. SB 221 required that Ohio's incumbent utilities obtain PUCO approval for either a Market Rate Offer (MRO) or an Electric Security Plan (ESP) to fulfil their standard service offer (SSO), or default service, obligations by the end of the aforementioned RSP period. The legislation also specified that these plans "exclude any previously authorised allowances for transition costs" (OLSC 2008). MROs represent a purer market-based rate-setting process in which the prevailing SSO rates are set by "competitive bidding process (CBP)" (OLSC 2008) auctions that tie generation pricing to actual wholesale market prices. ${ }^{12}$ ESPs utilise CBP auctions as well, but additionally allow for what energy attorneys refer to as "single-issue ratemaking". ${ }^{13}$ ESPs enable utilities to propose nonbypassable riders, which must be approved as a package in a single up or down vote by commissioners. Because ESP riders are not bypassable, their costs are incurred by all consumers regardless of whether they have switched to a marketer or remain on the SSO rate. Although MROs were the legislative default, utilities prefer ESPs because they greatly reduce the burden of obtaining additional revenue streams from consumers.

Under the rules of SB 221, utilities were required to simply demonstrate that ESP pricing was "more favourable in the aggregate as compared with the expected results that would otherwise apply under an MRO" (OLSC 2008). This became known as the "ESP versus MRO test". Because this test was unusually broad as compared with regulated ratemaking processes, all utilities obtained ESPs. Counter to the intentions of the legislature, to date, no MROs have been implemented. Utilities have no incentive to move to MROs, and thus lose the ability to obtain

\footnotetext{
${ }^{11}$ DP\&L's extended RSP stemmed from the utility's small size and limited resources. These constraints hindered DP\&L's ability to complete relevant PUCO proceedings and meet transition goals in a timely manner. Despite these initial delays, DP\&L underwent the same reforms as other utilities in the state.

${ }^{12}$ Ohio's CBP auctions for pricing default service - the first of their kind in the country - reduce the role of the PUCO in setting rates via negotiating and traditional rate-making formulas. Instead, auction markets determine the price for generating services through competitive bidding.

${ }^{13}$ ESPs allow for regulated "provisions related to the supply and pricing of electric generation" (OLSC 2008), including cost recovery and surcharges for transmission, distribution and related services, to remain. The ESP is less of a fully-market-oriented approach than the MRO. For example, FirstEnergy's latest ESP proposal "requests to add two new riders, modify 12 existing riders and remove six expiring riders" (PUCO 2016b).
} 
riders and surcharges. The existing ESP plans in effect for all four major IOUs include nearly three dozen additional nonbypassable riders. In addition, SB 221 did not substantively address divestiture or corporate separation, allowing incumbent utilities to continue arms-length ownership of generation.

SB 221 set in motion the competitive provision of electric services. ${ }^{14}$ Regulators believed that ESP plans allowed utilities "to 'ramp up' to market and operate under a blended generation price" (OLSC 2008) until an eventual MRO proposal. A PUCO staff investigation into the state of Ohio's retail electricity market between December 2012 and January 2014 argued that Ohio's hybrid form of restructuring achieved "effective competition" (PUCO 2012). ${ }^{15}$ The implementation of Ohio's retail restructuring (SB 221) is the most appropriate policy intervention point for this study. With SB 221's implementation, the state observed the end of regulatory rate review for pricing generation and the true opening of competitive retail choice, but also the beginning of nonbypassable riders and surcharges issued through single-issue ratemaking. The latter provided a means to circumvent the important deregulatory objective of unbundling.

\section{Data}

\section{Survey data}

The PUCO provides a monthly publication of utility rates in each utility service territory in Ohio conducted as part of its market evaluation and oversight function. These Ohio Utility Rate Surveys comprise the main source of data for this analysis. The surveys provide total electric bill charges for fixed consumption levels by customer class (i.e. residential, commercial and industrial). We note that in this article we focus solely on residential rates, which are the predominant focus of retail restructuring. The fact that the survey data include total bill information for fixed consumption levels is important to this study for three reasons.

First, total bill information is not commonly used in other analyses. The data source relied on for most studies to date has been EIA data (e.g. EIA 826), which provides an incomplete estimate of the marginal rate that customers pay for their electricity (i.e. cents/kWh) based on aggregate sales revenue reports of the distribution utility and excluding revenues obtained by riders and surcharges. ${ }^{16}$

\footnotetext{
${ }^{14}$ The initial round of ESP and MRO proposals was followed by considerable litigation between the utilities and the PUCO over "fair and equitable" and "excessive earnings" standards.

${ }^{15}$ More specifically, the PUCO staff recommended the structural separation of retail sales arm from former vertically integrated monopolies, $100 \%$ of SSO load procurement through competitive auctions and that customers have adequate access to information about retail services and products (PUCO 2012). Reviewing these standards, the PUCO staff found that "functional separation" and ongoing auction plans were sufficient and, absent some minor changes to billing formats, the competitive market was operational.

${ }^{16}$ EIA marginal prices are derived by two common metrics reported by utilities on quarterly and annual comprehensive reports (FERC Forms 1 and 3, respectively). EIA derives its marginal price estimates by dividing revenues reported by the distribution utility (i.e. the numerator) by total consumption of electricity by customers, including customers who switched to a competitive supplier (i.e. the denominator). The revenue component of the numerator includes only distribution company revenues, and excludes revenues obtained on customer bills that flow through to parent companies, arms-length subsidiaries and corporately separated gencos. Thus, EIA's marginal rate estimates deflate the numerator. In addition, by including even customers who have switched to competitive suppliers for their generation component, it inflates the denominator.
} 
Consequently, because this study uses actual customer final bill data, it relies on a more accurate representation of the actual costs incurred by households, including riders and surcharges that flow through to arms-length subsidiaries. Second, the data provide total bills for fixed consumption levels on a monthly basis. This is important, particularly given the quasi-experimental approach we use, because the data already inherently control for consumption and seasonal variation in demand for electricity. ${ }^{17}$ All of the electricity data reported in the surveys provide total bill costs for customers using $750 \mathrm{kWh}$. In this way, the surveys are not "surveys" as the term is typically used, but rather reflect what the commission views as a "typical bill" that is representative of a typical household. ${ }^{18}$

Third, the data are also helpful because they account for heterogeneity in tariff pricing structures across utilities and across time. That is, some utilities have pricing structures for some or all of their customers that utilise stepwise (also called "tiered") pricing rather than fixed rates. Under tiered pricing, utilities can charge higher marginal rates for higher consumption levels. Using fixed rate survey data eliminates the problem of accounting for differences in tiers between utilities and over time.

The surveys provide data only for SSO customers. CRES rates are contractual and based on the marketers' costs of procuring supply from the RTO. As such, there is heterogeneity across supply offers, in terms of both marginal rate and supplemental services offered (e.g. higher renewable percentages, longer-term fixed rate lock-ins). The fact that this study evaluates total customer costs based on SSO rates does not limit the explanatory power of our analysis. This is for two reasons. First, the SSO is by far the prevailing rate in Ohio's retail market throughout the time period studied. Appendix Table A.2 provides indicative counts of utility customers served by the default offer over time. As this table shows, the majority of residential customers served by major utilities - approximately $57 \%$, or 2.7 million customers - faced the SSO rate as recently as December 2015. The proportion of switched customers has plateaued over time. This is consistent with prior literature that has found that large subsets of residential customers are subject to inertia in restructured markets (Giulietti et al. 2005; Brennan 2007; Gamble et al. 2009; Yang 2014; Hortaçsu et al. 2017).

Second, customers who switch to a CRES supplier can only obtain a different price for the generation component of their bill. All of the other costs, inclusive of riders, as well as regulated T\&D, are nonbypassable, leaving the lion's share of the bill unchanged. In addition, the generation price for SSO and CRES customers should converge over time because both CRES and SSO rates are priced from the same wholesale market. Consequently, SSO rate data, as used here, are representative of the effects observed by all residential customers.

\section{Data summary and general trends}

The data span the years 2004 through 2015. In total, we use 144 monthly observations for each metro area. Table 1 below provides simple summary statistics in marginal rates $(\$ / \mathrm{kWh})$ that reflect the entirety of the bill that customers receive. This is an important distinction because utilities report to customers a lower

\footnotetext{
${ }^{17}$ Even with these inherent controls there are still seasonal features of our data (e.g. seasonally approved charges and variable costs) that present seasonality in some of our metro area time series, and which we appropriately account for by utilising seasonal components in our analysis.

${ }^{18}$ Average Ohio residential electricity consumption is $895 \mathrm{kWh} /$ month (EIA 2012).
} 
Table 1. Average total electricity bills (2004-2015)

\begin{tabular}{lccccc}
\hline & & Mean & & & \\
Service Territory & Utility Provider & $\begin{array}{c}\text { Monthly } \\
\text { Marginal Rate }\end{array}$ & $\begin{array}{c}\text { Standard } \\
\text { Deviation }\end{array}$ & Minimum & Maximum \\
\hline Akron & FirstEnergy (FE) & 0.134 & 0.007 & 0.116 & 0.150 \\
Canton & American Electric Power (AEP) & 0.113 & 0.022 & 0.088 & 0.164 \\
Cincinnati & Duke Energy (Duke) & 0.121 & 0.014 & 0.095 & 0.151 \\
Cleveland & FirstEnergy (FE) & 0.135 & 0.009 & 0.122 & 0.158 \\
Columbus & American Electric Power (AEP) & 0.129 & 0.019 & 0.102 & 0.182 \\
Dayton & Dayton Power and Light (DP\&L) & 0.133 & 0.014 & 0.112 & 0.159 \\
Toledo & FirstEnergy (FE) & 0.136 & 0.007 & 0.123 & 0.178 \\
\hline
\end{tabular}

Note: The values provided are marginal rates $(\$ / \mathrm{kWh})$ for the entirety of the electricity bill, inclusive of riders and surcharges. All values are in constant 2014 dollars.

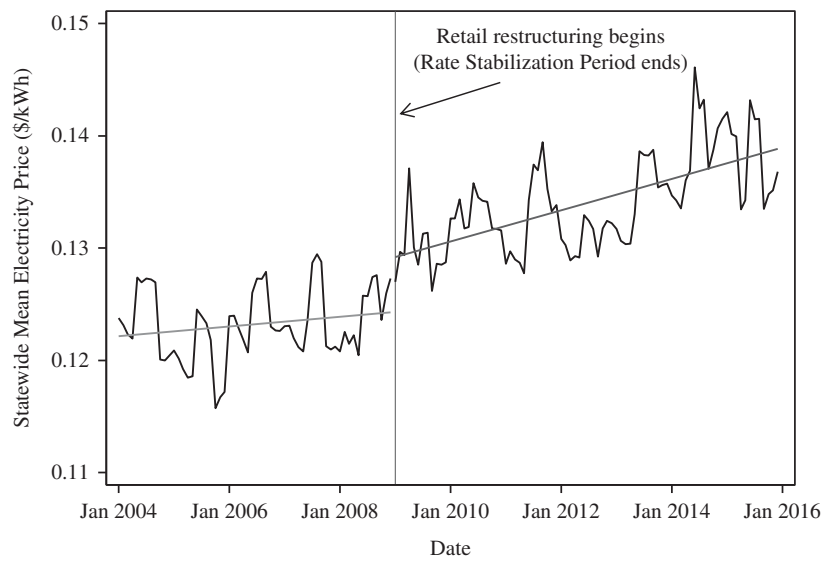

Figure 2. Statewide aggregate electricity price.

Note: Values reflect the mean, inflation-adjusted marginal rate for all utility service territories excluding Dayton Power \& Light (which restructured two years later).

marginal rate that only accounts for the generation costs. Bills for these customers averaged between 11 and 13 cents/kWh. They ranged between 8 cents and over 18 cents/kWh. Whereas Table 1 provides summary statistics within each of the major metro areas, we also provide the average by month across all of the metro areas to give a statewide aggregate electricity price. We show this as a time series plot in Figure 2. All time series data are adjusted by the general consumer price index to correct for inflation, and all values are reported in real 2014 dollars. ${ }^{19}$

It is clear that there is a general upward trend after retail restructuring and that it did not, in general, lower rates or keep rates constant. Whereas the mean statewide aggregate electricity price before restructuring was 12.63 cents/kWh, it was 13.29 cents following restructuring. Figure 2 excludes Dayton as it implemented restructuring two years later.

\footnotetext{
${ }^{19} \mathrm{We}$ avoid the use of electricity price CPI for inflation adjustment as it accounts for household electricity prices with an un-fixed consumption quantity, lags in inconsistent patterns with heterogeneous billing cycles and varies heterogeneously across geographic borders that are not necessarily contiguous to utility service areas.
} 


\section{Method of analysis}

\section{Interrupted time series (ITS) models}

We use an ITS design to evaluate the implementation of retail restructuring on default electricity prices (i.e. SSO price). ITS is a strong empirical approach for this particular application because it removes the time series pattern of data to provide an unbiased comparison of the pre- and post-retail restructuring periods given that electricity prices are measured at regular monthly intervals (Campbell and Stanley 1963; Abadie and Gardeazabal 1999; Shadish et al. 2002). In addition, as provided in the second section, ITS is contextually appropriate because the implementation of restructuring in Ohio provides for a clean policy intervention point (i.e. the implementation of SB 221) at which point traditional cost-of-service regulation for pricing generation ended.

Our null hypothesis is that the retail electricity price will have declined following the introduction of a market-basis for rate-setting, as purported by proponents of restructuring. Such changes can take two forms: a change in intercept (i.e. a change in the average electricity price after retail restructuring) or a change in slope (i.e. a change in the trend of electricity price after retail restructuring).

The general functional form of our model is given by:

$$
\begin{aligned}
\text { Price }_{t}= & \alpha+\beta_{1}\left(\text { Month }_{t}\right)+\beta_{2}(\text { Post-restructuring })+\beta_{3}\left(\text { Month }_{t}\right)(\text { Post-restructuring }) \\
& +\varepsilon_{t}
\end{aligned}
$$

Price $_{t}$ provides our explanatory variable of interest, electricity price in a given month $t$. Month $h_{t}$ is a month index beginning with our first available month of data, January 2004. The coefficient $\beta_{1}$ provides the general month-to-month price trend ignoring any intervention (i.e. the trend before retail restructuring). Postrestructuring is a dummy variable that provides the "interruption" of the series (i.e. our policy intervention point). Post-restructuring takes a value of " 0 " for months before restructuring, and a " 1 " for subsequent months during restructuring. The coefficient $\beta_{2}$ provides the change in the intercept of the electricity price trend after retail restructuring began. The coefficient $\beta_{3}$ of the interaction term $\left(\right.$ Month $\left._{t}\right)$ (Post-restructuring) provides the change in the month-to-month price trend between the pre-restructuring period and the restructuring period. Thus, it provides the difference in the slopes of the two trend lines (post-policy minus prepolicy).

The coefficient of the interaction term, $\beta_{3}$, could indicate a number of possible policy effects. For example, for any given model, if the coefficient is negative (and statistically significant), this indicates that restructuring had the effect of decreasing the pre-restructuring price trend for a given utility. We also note that a positive and significant $\beta_{3}$ would indicate the opposite effect, namely that the post-intervention monthly trend increased relative to before restructuring for all the same scenarios but in the opposite direction.

In addition, we note that lack of statistical significance of $\beta_{3}$ does not necessarily indicate a null finding. Lack of statistical significance of this coefficient should be taken, as a whole, in consideration with $\beta_{1}$ (which is the pre-restructuring trend). Proponents of retail restructuring argued that competitive retail markets would bring rates down. A positive and significant $\beta_{1}$ would indicate, for example, that prices were on the rise before retail restructuring. A nonsignificant $\beta_{3}$ would 
therefore indicate that restructuring did not have its intended effect, and that rates continued to rise after restructuring just as they had been rising on a monthly basis before.

The main modelling approach for accounting for this time series is the autoregressive integrated moving average (ARIMA) approach, which allows us to retain the controlled pre- and post-treatment effect measures while accounting for autocorrelation (Box and Jenkins 1970; Hamilton 1994; Box-Steffensmeier et al. 2014; Enders 2014). Properly correcting for autocorrelation is both theoretically and contextually important with this data, as household electricity prices in a given month tend to be highly correlated with prices in prior months. The structure of an ARIMA $(1,0,0)$ model is given by:

$$
\begin{aligned}
\left(1-\emptyset_{1} B\right) \text { Price }_{t}= & \alpha+\beta_{1}\left(\text { Month }_{t}\right)+\beta_{2}(\text { Post-restructuring }) \\
& +\beta_{3}\left(\text { Month }_{t}\right)(\text { Post-restructuring })+\varepsilon_{t}
\end{aligned}
$$

Building upon model (1), model $(2)$ adds $\left(1-\emptyset_{1} B\right)$ that indicates the autoregressive (AR) (1) process. $B$ is a backshift operator.

However, the data for some cities exhibit a fractionally integrated process. These cities are Canton, Columbus, Cincinnati and Dayton. First-differencing the data would lead to over-differencing based on the autocorrelation function (ACF) and partial autocorrelation function (PACF) plots. The fractional integration process has the characteristics of both unit root and stationarity. Similar to a stationary process, fractionally-integrated time series are mean reverting in the long run. In addition, similar to an integrated process (e.g. unit root), fractionally-integrated time series will exhibit strong dependence between observations over time. It has been argued that treating fractional integration as either unit root or stationary will threaten the validity of any statistical inferences (Sowell 1992; Baillie 1996; BoxSteffensmeier and Smith 1998). Thus, we use an autoregressive fractional integrated moving average (ARFIMA) model that allows the integrated order $(d)$ to take noninteger values (i.e. fractions).

The selection of AR and MA orders are based on the diagnosis of the characteristics of electricity price data for given utility service areas, which will be discussed later in more detail. Generally, the time series for the utility service areas associated with fractional integration can be best fit into the ARFMA $(1,0,0)$ model, as given by:

$$
\begin{aligned}
(1-B)^{\mathrm{d}}\left(1-\emptyset_{1} B\right) \text { Price }_{t}= & \alpha+\beta_{1}\left(\text { Month }_{t}\right)+\beta_{2}(\text { Post-restructuring }) \\
& +\beta_{3}\left(\text { Month }_{t}\right)(\text { Post-restructuring })+\varepsilon_{t}
\end{aligned}
$$

Building upon model (2), model (3) adds one variable: the estimate of fractional integration $(d)$. Our hypothesis suggests that electricity prices should ceteris paribus decrease after restructuring for one of the above-mentioned four scenarios. Therefore, we expect the coefficient of the interaction term $\left(\beta_{3}\right)$ to be negative, which means restructuring has a negative impact on the fractionally-differenced electricity price.

For some service areas, we use a seasonal autoregressive integrated moving average (SARIMA) model to handle the added complexity of seasonality. These cities are Akron, Cleveland and Toledo. The SARIMA model is often denoted as an 
ARIMA $(p, d, q) \times(P, D, Q)_{s}$. On the basis of the diagnosis details that are discussed later, the electricity data for utility service areas with significant seasonality can be best estimated by the ARIMA $(1,0,0) \times(1,0,0)_{12}$, given by:

$$
\begin{aligned}
\left(1-\emptyset_{1} B\right)\left(1-\Phi_{1} B^{12}\right) \text { Price }_{t}= & \alpha+\beta_{1}\left(\text { Month }_{t}\right)+\beta_{2}(\text { Post-restructuring }) \\
& +\beta_{3}\left(\text { Month }_{t}\right)(\text { Post-restructuring })+\varepsilon_{t}
\end{aligned}
$$

Model (3) adds the seasonal AR (1) component $\left(1-\Phi_{1} B^{12}\right)$ and the AR (1) component $\left(1-\emptyset_{1} B\right)$ to model (2). Similar to models (2) and (3), a negative coefficient of the interaction term $\left(\beta_{3}\right)$ would support the conclusion that restructuring lowered retail electricity prices.

\section{Model selection}

Our approach to model selection began with diagnosing the time series properties of the electricity price data for each utility service area; this is consistent with the long-standing approach taken by Box and Jenkins (1970). We first used the generalised Box-Jenkins approach of reviewing the ACF plots and PACF plots for each city to examine whether electricity prices exhibit unit root and seasonality (see Appendix Figure A.1). Electricity prices in Canton, Cincinnati, Columbus and Dayton have significant spikes even after 10 lags. Such patterns suggest that the data for those territories probably exhibit a unit root. Moreover, the periodic spikes around every 12 intervals (months) suggest that electricity prices in Akron, Cleveland and Toledo exhibit yearly seasonality. We note that the main utility provider for these cities is FirstEnergy.

Second, we use two formalised tests to complement the evidence obtained from the visual diagnosis of stationarity: the widely used Dickey-Fuller test and Variance Ratio Test (Dickey and Fuller 1974; Lo and MacKinlay 1988). Appendix Table A.3 provides the results of Dickey-Fuller tests (including time trend). We fail to reject the null hypothesis that electricity prices in Canton, Cincinnati, Columbus and Dayton exhibit unit root behaviour with trend. The Dickey-Fuller test results are consistent with our visual diagnosis.

However, some scholars argue that the Dickey-Fuller test has less definitive power, which means that we may too easily accept that we have a unit root for those territories in the face of fractional integration (Box-Steffensmeier et al. 2014). To compensate for that potential weakness in the Dickey-Fuller test, we also run variance ratio tests for which the null hypothesis is a unit root (the integrated order $\mathrm{d}=1$ ). The alternative hypothesis suggests that either a fractional integration or stationarity $(\mathrm{d}<1)$ is appropriate. Appendix Table A.4 presents the results of the variance ratio tests for various choices of the differencing interval (2, 4, 8 and 16 months). As the results suggest, the null hypothesis that the series has a unit root can be rejected for Toledo at all differencing intervals. We fail to reject the null hypothesis of a unit root for Cincinnati and Columbus at all differencing intervals. For the other four cities (Akron, Canton, Cleveland and Dayton), the variance ratio tests reject the null hypothesis at some differencing intervals. This implies that the series are probably fractionally integrated.

Finally, the hyperbolic decay in the ACF and a significant spike at the first lag in the PACF suggest that the electricity prices in all cities exhibit an AR (1) process. 
For Akron, Cleveland and Toledo, we also detect a seasonal AR (1) component in the corresponding PACF plots as the spikes around the 12th lag are significant. ${ }^{20}$

On the basis of the diagnostic results and the performance of multiple competing models on the post-estimation tests (e.g. nonlinearity tests, white noise tests and information criterion), we identify the strongest model fit for Akron and Toledo to be an ARIMA $(1,0,0) \times(1,0,0)_{12}$ model, and an ARIMA (2, 0, $0) \times(1,0,0)_{12}$ to best fit Cleveland. Similarly, we identify the strongest model for Cincinnati, Columbus and Dayton to be an ARFIMA $(1,0,0)$ model. Finally, we identify the strongest model for Canton to be an ARIMA $(1,0,0)$ model given that the ARIMA $(1,0,0)$ has almost equal performance on the post-estimation tests as a more complicated ARFIMA $(1,0,0)$ suggested by the diagnostic results, but with a higher degree of parsimony.

We conduct Enders' Regression Equation Specification Error Test (RESET) to identify any nonlinearity in the pre- versus post-policy intervention data (Appendix Table A.5) for the specified models. The test results reject significant structural changes in the electricity price data for all seven metro areas. We also provide Portmanteau and Bartlett's white noise test statistics ( $Q$ and B statistics, with accompanying p-values) of each preferred model for the period preceding regulatory restructuring, the period following and for the full series (Appendix Table A.6). In all cases, the data fail to reject the null (of white noise) at least at the 0.05 level or higher, indicating that there is no unobserved heterogeneity bias in the residuals. The two most marginal cases are the pre-restructuring period for Canton and the post-restructuring period for Cleveland, which marginally pass at 0.05 on only a single test, but pass handily on the other test, respectively. ${ }^{21}$ The white-noise residuals across both the pre- and post-restructuring periods provide robust evidence of the absence of structural breaks, as the same autoregressive process fits the data for both periods.

\section{Empirical results}

\section{Price trend summary}

While proponents of market-based rate-setting of retail electric service have argued that converting regulated rates to market-based rates will reduce them, the results of our analyses provide little confirmation - and, in some cases, provide a direct refutation - of that claim. While in Figure 2 we provide the aggregate statewide time series plot of electricity prices, in Figure 3 we provide this for each of the seven major metro areas/utility service areas in Ohio, in Figure 3a-3g.

The data suggest that Akron, Cleveland and Toledo were experiencing downward trending electricity prices before the implementation of SB 221. Although Cleveland and Toledo experienced a decrease or cessation of that downward trend after implementation, Akron experienced a direct reversal. For Akron, the prerestructuring downward trend in electricity bills became an upward trend. Canton, on the other hand, experienced a slight upward (if not flat) trend before retail

\footnotetext{
${ }^{20}$ The PACF plots delineate a significant spike at the 13th lag. However, the seasonal order is more likely to be 12 months according to the periodic patterns in the ACF plots.

${ }^{21}$ For purposes of the white noise test only, we recoded four outlier months (three in Canton and one in Toledo) that represent anomalous high-price winter months in the data (e.g. the Polar Vortex). Both white noise tests are highly sensitive to outliers so the authors viewed this as appropriate.
} 

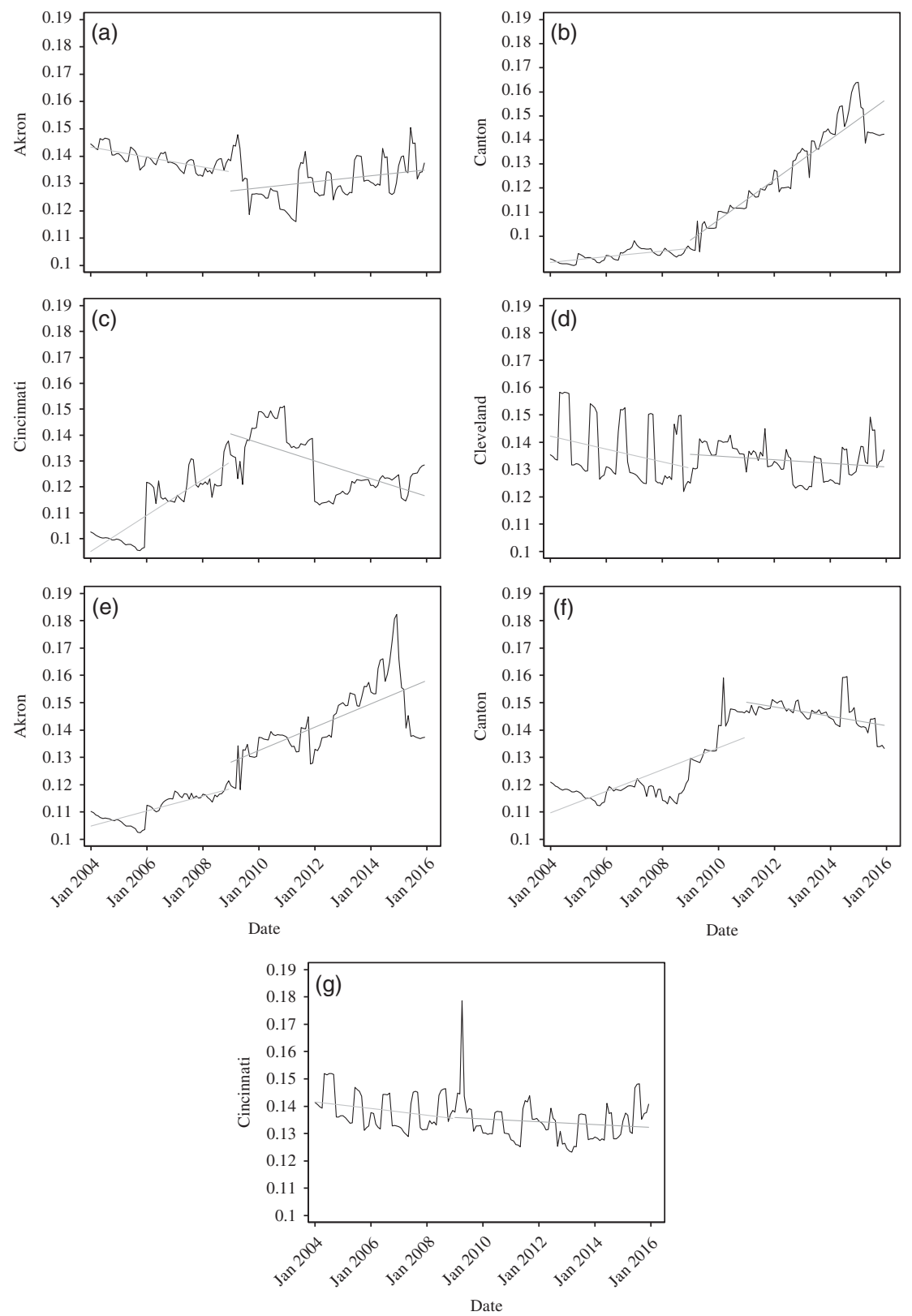

Figure 3. Interrupted time series plots. (a) Akron, (b) Canton, (c) Cincinnati, (d) Cleveland, (e) Columbus, (f) Dayton and (g) Toledo.

restructuring that was turned abruptly and significantly upwards thereafter. The capital city of Columbus was experiencing a steady increasing trend in electricity prices before retail restructuring and that trend continued at essentially the same rate thereafter. In addition, although the post-restructuring prices there maintained 
a similar trend, the average prices are higher than the prices that would have resulted had the prior trend continued.

Cincinnati and Dayton differ from the rest of the state. Both Cincinnati and Dayton were experiencing increasing trends in electricity prices before retail restructuring. The pre-restructuring increasing trends were altered, and turned clearly and abruptly downwards for Cincinnati. Post-retail restructuring prices in both metro areas exhibited higher average prices than before retail restructuring.

\section{Interrupted time series regression results}

In Table 2, we provide the results of our time series models. The models have relatively strong fitness and summary measures as indicated by the Akaike Information Criterion (AIC) and Bayesian Information Criterion (BIC) statistics, indicating strong predictive power of the models overall. All model coefficients reported are in cents per kWh. Recalling that the coefficients for "Month" indicate the pre-retail restructuring price trend, we see that the coefficients all align quite closely with visual inspection of the times series plots. This coefficient is statistically significant at the $10 \%$ level for all metro areas with the exceptions of Cleveland and Toledo, which come close to statistical significance but exhibit strong seasonal variation that inflates the standard errors on even the most robust linear fit. The statistical significance of model fitness for the pre-restructuring time period gives us strong confidence in our difference (i.e. policy) measure, the interaction term, which we discuss next.

The policy effect is provided in the interaction term. The interaction term, indicated by "Post $2009 \times$ Month", is generally robust and similarly confirmed by visual inspection of the time series plots. Recall that the magnitude of the coefficient indicates the difference between the pre- and post-restructuring trends. In addition, recall that the statistical significance of that coefficient indicates the degree to which we can reject the null of pre-post price trend equality. This is important because lack of statistical significance of this coefficient does not indicate that the time series model does not fit the post-restructuring data in a robust manner; it indicates that there is no statistical difference between the slopes of the two trend lines. See Columbus, for example. Prices were rising on a monthly basis before retail restructuring in that service territory and continued to rise thereafter. The lack of statistical significance of the interaction term indicates that retail restructuring had no statistically significant effect on reducing the rising costs of electricity as purported - they continued to rise in Columbus.

For the FirstEnergy territory (Akron, Cleveland and Toledo), we see consistent decreasing prices before retail restructuring. Cleveland and Toledo continued to experience decreasing prices following retail restructuring but at a decreasing (prices falling less quickly) rate. For those two cities, we fail to reject the null that retail restructuring had an effect. For Akron, as mentioned above, we see a direct reversal in price trend that is statistically significant; an average monthly policy effect of increasing prices by 0.0275 cents/kWh. The post-retail restructuring price trend in Akron is 0.0064 cents/kWh (i.e. the pre-policy trend of -0.0211 cents plus the change/interaction term of 0.0275 cents). For residents in the Akron area who use an average of $750 \mathrm{kWh}$ of electricity each month, the effect of retail restructuring translates to monthly increases in bills of approximately 21 cents above what would have been expected had the robust pre-retail restructuring trend gone uninterrupted. 
Table 2. Regression results

\begin{tabular}{|c|c|c|c|c|c|c|c|}
\hline & Akron & Canton & Cincinnati & Cleveland & Columbus & Dayton & Toledo \\
\hline & $\begin{array}{c}\text { ARIMA }(1,0,0) \times \\
(1,0,0)_{12}\end{array}$ & ARIMA $(1,0,0)$ & ARFIMA $(1,0,0)$ & $\begin{array}{c}\text { ARIMA }(2,0,0) \times \\
(1,0,0)_{12}\end{array}$ & ARFIMA $(1,0,0)$ & ARFIMA $(1,0,0)$ & $\begin{array}{c}\text { ARIMA }(1,0,0) \times \\
(1,0,0)_{12}\end{array}$ \\
\hline Post 2009 & $-1.8320(0.951)^{\star}$ & $-3.2005(0.7022)^{\star \star \star}$ & $4.5050(1.525)^{\star \star \star}$ & $-1.2492(1.0645)$ & $0.0367(1.464)$ & & $-0.8755(0.8921)$ \\
\hline Month & $-0.0211(0.0060)^{\star \star \star}$ & $0.0138(0.0041)^{\star \star \star}$ & $0.0689(0.0159)^{\star \star \star}$ & $-0.0206(0.0140)$ & $0.0349(0.0120)^{\star \star \star}$ & $0.0363(0.0108)^{\star \star \star}$ & $-0.0137(0.0084)$ \\
\hline $\begin{array}{l}\text { Post } \\
2009 \times \text { Month }\end{array}$ & $0.0275(0.0124)^{\star \star}$ & $0.0554(0.0092)^{\star \star \star}$ & $-0.0813(0.0248)^{\star \star \star}$ & $0.0239(0.0182)$ & $-0.000481(0.0213)$ & & $0.0151(0.0137)$ \\
\hline $\begin{array}{l}\text { Post } 2011 \\
\quad \text { (Dayton only) }\end{array}$ & & & & & & $4.1691(1.6898)^{\star \star}$ & \\
\hline $\begin{array}{l}\text { Post } 2011^{*} \\
\text { Month } \\
\text { (Dayton only) }\end{array}$ & & & & & & $-0.0459(0.0204)^{\star \star}$ & \\
\hline $\operatorname{AR}(1)$ & $0.7540(0.0771)^{\star \star \star}$ & $0.7503(0.0887)^{\star \star \star}$ & $0.8900(0.0512)^{\star \star \star}$ & $0.4178(0.1230)^{\star \star \star}$ & $0.9070(0.0593)^{\star \star \star}$ & $0.3625(0.2251)$ & $0.7250(0.0712)^{\star \star \star}$ \\
\hline AR (2) & & & & $0.1395(0.0905)$ & & & \\
\hline $\operatorname{AR}(1)_{12}$ & $0.3690(0.131)^{\star \star \star}$ & & & $0.6388(0.1468)^{\star \star \star}$ & & & $0.5783(0.1092)^{\star \star \star}$ \\
\hline d & & & $-0.0304(0.0673)$ & & $-0.0616(0.1270)$ & $0.4557(0.0598)^{\star \star \star}$ & \\
\hline$\sigma^{2}$ & $0.1384(0.0369)^{\star \star \star}$ & $0.1143(0.0368)^{\star \star \star}$ & $0.1810(0.0546)^{\star \star \star}$ & $0.2964(0.0493)^{\star \star \star}$ & $0.1660(0.0374)^{\star \star \star}$ & $0.1151(0.0364)^{\star \star \star}$ & $0.1458(0.0288)^{\star \star \star}$ \\
\hline Constant & $14.4200(0.1600)^{\star \star \star}$ & $8.8610(0.1132)^{\star \star \star}$ & $9.5030(0.5660)^{\star \star \star}$ & $14.3115(0.6314)^{\star \star \star}$ & $10.4400(0.4370)^{\star \star \star}$ & $11.1859(0.8269)^{\star \star \star}$ & $14.2641(0.3877)^{\star \star \star}$ \\
\hline Log-likelihood & -63.20 & -48.60 & -81.91 & -120.06 & -75.57 & -50.1895 & -68.5373 \\
\hline Wald $\chi^{2}$ & $159.64^{\star \star \star}$ & $525.10^{\star \star \star}$ & $547.85^{\star \star \star}$ & $145.17^{\star \star \star}$ & $650.38^{\star \star \star}$ & $581.02^{\star \star \star}$ & $137.66^{\star \star \star}$ \\
\hline AIC & 140.40 & 109.20 & 177.81 & 256.12 & 165.14 & 114.38 & 151.07 \\
\hline BIC & 161.18 & 127.02 & 198.60 & 279.88 & 185.93 & 135.17 & 171.86 \\
\hline
\end{tabular}

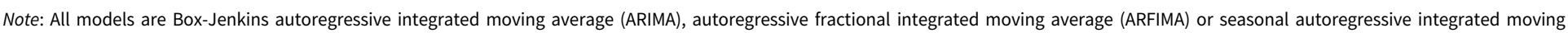
average (SARIMA) and use the robust estimator of variance. $n=144$ months.

Standard errors in parentheses ${ }^{\star \star \star} p<0.01,{ }^{\star \star} \mathrm{p}<0.05,{ }^{\star} \mathrm{p}<0.1$. 
Table 3. Pre- and post-retail restructuring mean monthly electric prices by metro area

\begin{tabular}{lcc}
\hline Service Territory/Metro Area & $\begin{array}{c}\text { Mean Monthly Electricity Price } \\
\text { (Pre-Retail Restructuring) }\end{array}$ & $\begin{array}{c}\text { Real Mean Monthly } \\
\text { Electricity Price } \\
\text { (Post-Retail Restructuring) }\end{array}$ \\
\hline Akron & 13.89 & 13.11 \\
Canton & 9.20 & 12.72 \\
Cincinnati & 11.21 & 12.86 \\
Cleveland & 13.64 & 13.32 \\
Columbus & 11.15 & 14.30 \\
Dayton & 12.34 & 14.60 \\
Toledo & 13.86 & 13.36 \\
\hline
\end{tabular}

Note: Values represent the average of monthly values across all months in our sample. All values are in constant 2014 cents/kWh.

For the AEP service territory (Canton and Columbus), the pre-retail restructuring trends in electric prices were a statistically significant monthly increase of 0.0138 and 0.0349 cents/kWh, respectively. The post-retail electric restructuring price trend for those cities has been 0.0692 and 0.0344 cents/kWh, respectively. As also indicated by the time series plots, Canton (formerly the Ohio Power service area) experienced a significant monthly price increase of 0.0554 cents $/ \mathrm{kWh}$, which is both large in magnitude and highly statistically significant. Columbus experienced no statistically significant policy effect; prices continued to rise after restructuring as they had been rising before restructuring. For residents in the Canton area who use an average of $750 \mathrm{kWh}$ of electricity each month, the effect of retail restructuring translates to monthly increases in bills of approximately 41.55 cents above what would have been expected had the robust pre-retail restructuring trend gone uninterrupted.

For the Duke Energy service territory in the Cincinnati metro area, as well as for the DP\&L service territory in the Dayton area, the data indicate a more favourable effect. For both areas, the data suggest that the pre-retail restructuring trend of electric prices increasing by 0.0689 cents $/ \mathrm{kWh}$ each month has effectively been reversed. The effect of retail restructuring has been a monthly decline of over 0.081 and 0.046 cents/kWh for Cincinnati and Dayton, respectively. The postrestructuring monthly price trend in Cincinnati has been a monthly decline of $0.0124(-0.0813+0.0689)$ cents/kWh. For Dayton this figure is a 0.0096 cents $/ \mathrm{kWh}$ decline. For residents in the Cincinnati area who use an average of $750 \mathrm{kWh}$ of electricity each month, the effect of retail restructuring translates to monthly decreases in bills of approximately 60.98 cents below what would have been expected had the robust pre-retail restructuring trend gone uninterrupted. For the Dayton area this figure is an average monthly price decrease of approximately 34.4 cents.

One complicating factor in interpreting these results is the intercept term associated with the post-policy trend line. For several of the areas in our study, the policy change point at which retail restructuring was implemented is given by a change in the intercept term. For example, the monthly declines in Dayton's prices after retail restructuring do not necessarily mean that residents in the Dayton area are paying less on average for their electricity in real terms. We therefore provide the change in the intercept for each city in our regression outputs in Table 2, which 
is the coefficient on the policy intervention dummy variable. This change represents the difference between the $y$-intercept of the pre-restructuring trend and the $y$-intercept of the post-restructuring trend (at the beginning month of our sample, January 2004). Accounting for this, we see a downward (post-policy) change for Akron, and an upward change for Canton, Cincinnati, Cleveland, Columbus and Dayton. Moreover, we provide further insight by calculating the monthly pre- and post-policy averages in constant cents in Table 3. We note that both of the cities that exhibit downward (i.e. favourable) reversals in electric price trends (Dayton and Cincinnati) have been paying more in real terms for each $\mathrm{kWh}$ of electricity after retail restructuring, accounting for the post-policy intercept.

\section{Welfare effects}

We extend our price impact analysis one step further by estimating welfare impacts for each of our seven metro areas and the state as a whole. By welfare, we mean the cumulative net total out-of-pocket expenditure differential of all residents in the seven major utility service areas that have electric service through their distribution utility (i.e. SSO customers) in the time since retail restructuring took effect in each respective service territory. In other words, we estimate the costs SSO customers would not have had to pay if the general pre-retail restructuring price trend continued. To accomplish this, we use quarterly customer count data from the PUCO. These customer count data provide the total customer counts for SSO customers and CRES customers. ${ }^{22}$ We construct a counterfactual linear trend forecast of the pre-retail restructuring period from the trend already embedded in our models (e.g. the slope when the policy intervention binary variable is 0 ). From this, we develop linear trend forecasts for each metro area to estimate what these customers would have paid if the pre-restructuring price trend had persisted. We provide these estimates as a reasonable lower-bound approximation; higher costs for customers using above $750 \mathrm{kWh}$ each month and similar costs for customers receiving CRES service are not included. In addition, these are only direct effect estimates and do not include any macroeconomic (i.e. direct + indirect) impacts that have been experienced by the state or the region more broadly, which could be nearly twice the magnitude.

Table 4 provides our welfare estimates as cumulative total (net) loss estimates for each service territory for all months since retail restructuring. We estimate the lower-bound statewide net effect of retail restructuring on residential SSO customers to be around $\$ 1$ billion in losses. By far, the largest net losses have been incurred in AEP's service territory (central Ohio areas of Columbus and Canton). The net effect on customers in the Dayton territory has been relatively minor for

\footnotetext{
${ }^{22}$ The 2012 merger of the two AEP-owned companies Columbus Southern Power and Ohio Power represent a peculiarity in our data that requires a simplifying assumption in utilising the PUCO's customer count data. After 2012, the PUCO no longer distinguished between customers in Canton (Ohio Power territory) and Columbus (Columbus Southern territory), and instead provides only customer totals for all AEP service territories combined. This is not the case for price data, however. We assume that the ratio of total customers in the two combined service territories has not changed significantly since 2011 (the last known customer count year that is separated by the two service areas), at approximately 48 and $52 \%$ for Canton and Columbus, respectively. We also assume that the AEP switching rates (i.e. proportion of customers who switched to a CRES provider) are homogenous across all of the post-merger AEP service territory.
} 
Table 4. Estimated net welfare change from retail restructuring

\begin{tabular}{lr}
\hline Service Territory/Metro Area & Net Welfare Loss \\
\hline Akron & $+\$ 12,927,621$ \\
Canton & $-\$ 848,899,035$ \\
Cincinnati & $+\$ 544,190,655$ \\
Cleveland & $-\$ 139,312,795$ \\
Columbus & $-\$ 515,107,782$ \\
Dayton & $+\$ 35,268,959$ \\
Toledo & $-\$ 8,911,410$ \\
Total (statewide net) & $-\$ 919,843,786$ \\
\hline
\end{tabular}

Estimates reflect cumulative welfare change for residential SSO customers in constant 2014 dollars by utility service territory (metro area) between the implementation of retail restructuring and December 2015.

the fewer years in which retail restructuring has been in effect there. On the other hand, we estimate the Duke Energy service territory (i.e. Cincinnati metro area) to have net welfare gains of over $\$ 500$ million. As is clear from Figure 3c, Cincinnati exhibited a significantly positive increasing trend in prices before retail restructuring, and we similarly assume that this trend would have continued for the purposes of these welfare estimates.

\section{Discussion}

It is important to acknowledge the complementary arguments about what the results show. One argument could suggest that the baseline of our analysis is corrupt, and would emphasise that the pre-restructuring period represents a "rate freeze" period in which rates were held fixed. This argument continues by suggesting that rates during this period were "uneconomic" and did not fully reimburse utilities for stranded costs. This implies that rates were expected to climb after the end of the rate freeze period. We disagree with this argument. The PUCO approved cost recovery to utilities for stranded costs during the market development period at a favourable rate of return on equity. In addition, the PUCO specifically allowed for the RSP to account for any exogenous shocks, therefore allowing for this form of rate increase in the time before the implementation of SB 221. There was thus no pent-up need for additional recovery for stranded costs after the implementation of SB $221 .^{23}$

Another competing argument would suggest that, after the implementation of retail restructuring, distribution utilities experienced an increase in costs affecting the regulated component of consumers' bills, such as T\&D. T\&D costs are driven by a variety of factors, including changes in customer service requirements, policy and perverse incentives (e.g. gold plating). We would not expect changes in T\&D

\footnotetext{
${ }^{23}$ The language of SB 221 is clear on this point. It reads: “The utility's receipt of transition revenues shall terminate at the end of the market development period. With the termination of that approved revenue source, the utility shall be fully on its own in the competitive market. The commission shall not authorize the receipt of transition revenues or any equivalent revenues by an electric utility except as expressly authorized in sections 4928.31 to 4928.40 of the Revised Code" (see ORC 4928.38).
} 


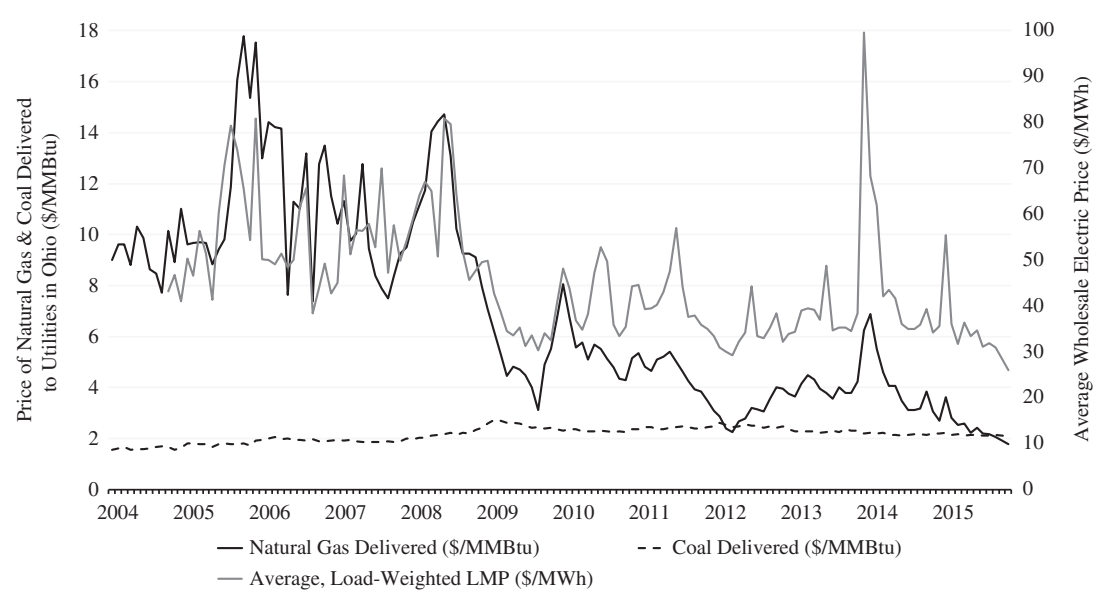

Figure 4. Wholesale price of electricity, natural gas and coal in Ohio.

Note: Values in inflation-corrected dollars per million metric British Thermal Units (BTUs) for gas and coal, and megawatt hours (MWh) for electricity. Wholesale prices reflect the average of each utility's zonal load-weighted locational marginal price (LMP). Each utility's load-weighted LMPs are calculated using hourly price and load data from PJM Interconnection, Midcontinent Independent Systems Operator and MarketViews. Natural gas and coal prices reflect the monthly final delivery price of each to electric generation in Ohio (inclusive of transportation costs).

Source: EIA Electric Power Monthly (EPM), Table 4.10A. The spike in January 2014 reflects the Polar Vortex.

costs during the study period to affect the observed price for several reasons. First, demand was flat or declining, undermining the premise that costs increased owing to new infrastructure required to meet growing load. Second and relatedly, the PJM Interconnection (PJM) RTO oversees transmission expansion for its wholesale market participants. In this role, PJM is the ultimate arbiter of which projects are required for reliability, as well as managing the competitive allocation of projects to least-cost developers (not necessarily the incumbent utilities). This system diminishes the incentive for excessive or unnecessary grid upgrades intended to inflate the rate base; the cost for major transmission upgrades are not subject to guaranteed rate recovery by load-serving utilities. Third, utilities in Ohio faced strict reliability standards and were expected to continue maintenance of T\&D throughout the transition period. There is no publicly available evidence that customers experienced major changes in system reliability owing to deferred upgrades.

Another related competing argument would suggest that the residential price increases observed by households were owing to increases in wholesale costs associated with generation (e.g. fuel costs, pollution compliance). This alternative argument is misinformed. Because Ohio also restructured its wholesale markets, all generation in Ohio bids into the larger PJM regional market. Generation-related costs are incorporated into the wholesale price. To illustrate wholesale market developments, in Figure 4 we provide the average historical wholesale price of electricity observed by distribution utilities in Ohio, alongside the prices of the predominant fuel inputs of natural gas and coal. Both natural gas and coal price provide the final delivery price (inclusive of shipping costs) to electric generation units in Ohio. The wholesale price provides monthly load-weighted average 
locational marginal price (LMP) based on hourly load and pricing data from PJM and the Midcontinent Independent Systems Operator (MISO). It is noteworthy that we observe across the board significant price declines in the final wholesale price of electricity, inclusive of all generation-related costs, coincident with the shale boom during which prices for the marginal market clearing generation resource, natural gas, declined. Given this, arguments that residential price increases observed by households are due to increases in some unexplained components of wholesale costs are misguided.

A core theoretical objective of deregulation is to bring retail and wholesale prices closer towards convergence, so that consumers' fortunes are not tied to the fortunes of any one regional monopoly. It is striking that, with the implementation of retail restructuring in Ohio, we observe an inverse relationship between historic price declines in wholesale markets and historic price increases in retail price. One would expect that some of the savings from the wholesale market would be passed on to households - the "promise" of deregulation. The fact that we observe this for only one utility (Duke Energy), and the fact that this was the only utility in the state to functionally - rather than corporately - divest (or unbundle) its generation, is of critical interest. Duke Energy sold the near entirety of its generation to the wholesale generation firm Dynegy, except for a small co-ownership in a rural cooperative. The other three utilities retained arms-length ownership of their generation assets, predominantly legacy coal plants, with the exception of the Davis-Besse nuclear plant owned by a FirstEnergy subsidiary. As such, except for Duke Energy, the other three utilities took long positions in coal when the shale boom hit. With the implementation of SB 221, regulatory provisions allowing single-issue ratemaking afforded utilities an expedient path to offset their generation losses through nonbypassable riders and surcharges. Duke Energy, by selling its generation assets, did not observe comparable losses and therefore did not have the same instrumental incentive to obtain riders and surcharges.

Our identification of welfare losses for residential customers bares important questions about the political economy of retail restructuring. Of particular interest is welfare transfers to utilities. Blumsack et al. (2008), for instance, argue that the efficiency gains realized by utilities under restructuring are not passed on to residential consumers owing to increased transaction costs and a reallocation of risk. Price (2005), in her discussion of the welfare consequences of liberalisation in the United Kingdom, notes a variety of market power concerns through which incumbent utilities can exploit switching costs at the expense of the vulnerable residential class. In general, it is not apparent that retail restructuring can successfully eliminate complicated vestigial relationships and political pressure between utilities and regulators. Instead, our findings match the liberalisation "lesson" that incomplete or incorrect implementation risks substantial costs (Joskow 2008).

Finally, our research runs counter to arguments that there is a benefit to a high SSO insofar as it encourages switching behaviour. To the extent that we treat the SSO as distinct from CRES rates, this argument is challenged by the substantial number of customers who have not switched. Moreover, it is important to bear in mind that distribution utilities are indifferent regarding switching rates because they observe no direct change in revenue if switching rates change. They have no direct incentive to keep the SSO low to retain market share. In the extreme case of a $0 \%$ switch rate, all generation revenue would be passed on to CBP auction tranche 
winners and not retained by the utility. In the opposite extreme case of a $100 \%$ switch rate, all generation revenue would flow through to CRES suppliers. Similarly, our findings contrast arguments in support of the claim that the costs of retail deregulation are front-loaded (mostly through stranded cost recovery) and the benefits are back-loaded. There is no immediate evidence to suggest that riders and tariffs will not continue to grow via subsequent regulatory action.

Retail restructuring has brought with it the ability for residential customers to exercise their Tieboutian option to "vote with their feet". Customers can switch away from the SSO provided by the monopoly utility in their region and contract with a CRES provider. This behaviour can provide a variety of benefits outside the scope of this study. However, we similarly acknowledge that under Ohio's retail restructuring regime, the majority of the riders, surcharges and T\&D charges are unchanged by opting out to a CRES provider. Thus, any potential benefits of switching are heavily muted.

\section{Conclusions and implications}

The promise of retail electric deregulation was that moving to a market-based pricing system would set more favourable rates for households than prices determined exclusively by a regulatory commission. This article provides a quasiexperimental analysis of retail electric prices for all investor-owned utility service territories in the State of Ohio. It provides a controlled pre- and post-test of the effect of retail electric restructuring on residential SSO prices that are paid by millions of households. The results bring into relief the contrast between theory and practice. For most of Ohio's residential retail load, prices have not declined since retail restructuring. For four of the seven metro areas in the state, retail restructuring resulted in higher month-to-month price trends than existed before restructuring. In addition, although the other three territories of Cincinnati, Columbus and Dayton have seen month-to-month price trends either not change or decline, relative to pre-restructuring, households in those territories paid a higher real (inflation-adjusted) price, on average, in the period following restructuring than they did in the period preceding. At a time when wholesale electricity prices were historically low, millions of households observed price increases despite price declines in the markets upon which their rates were supposedly based.

The ultimate question that this article should motivate is whether the observed failures are because of the manner in which retail deregulation was implemented or because of failures inherent to the underlying deregulatory theory. We would argue the former without jumping unnecessarily to the latter. Students and scholars of the public policy process have long understood many of the core pitfalls of policy implementation (Sabatier and Mazmanian 1980; Mazmanian and Sabatier 1981; Huber and Shipan 2002; Hill 2003). In complex policy environments that require advanced knowledge, such as electricity markets, policymakers tend to ascribe a high degree of discretion to technical experts, such as public utilities commissions (Radaelli 1995, 2004; Esterling 2009). The Ohio legislature, in drafting the two pieces of legislation that initiated retail deregulation (SB 3 and later SB 221), diverged from the standard "textbook" model of retail restructuring that called for unbundling, or divestiture, of electric generation (power plants) from distribution (local service). They did this by requiring "corporate", rather 
than functional, separation. In using this ambiguous language, they afforded a high degree of deference to the commission to implement this core prerequisite of deregulation.

Both policy scholars and political economic theorists recognise that statutory ambiguity, combined with a high degree of discretion exercised by implementers, creates conditions that cultivate rent-seeking (Krueger 1974; Wright 1977; Tullock 2001; Mahoney and Thelen 2010; Carter et al. 2015). In this article, we identify two implementation steps taken by the commission that we believe drive the results of this study. One, in approving each public utility's corporate separation plan, they permitted a broad statutory application that allowed utilities to create arms-length affiliate corporations to which they divested their plants (almost entirely legacy coal). Two, they allowed utilities to pursue a hybridised tariff system, known as an ESP, that permitted utilities to add nonbypassable riders (almost three dozen) to household electric bills. Ohio's retail restructuring legislation (SB 221) required that utilities eventually transition to only using competitively determined MROs for setting SSO rates, and also created an ESP versus MRO test to ensure that ESPs were more favourable in the aggregate as compared with MROs. However, by adopting broad language for this test and not establishing a timeline to adopt MROs, the legislature again deferred to the PUCO.

PUCO, in enforcing ESPs, adopted "single-issue" ratemaking approval for ESPs rather than comprehensive regulatory review, meaning proposed costs are subject to less rigorous review than before retail restructuring. As a consequence, utilities have wide discretion to pursue riders as a nonbypassable revenue source imposed on all customers. In the historical context of the shale boom, this created a rentseeking incentive in order to offset the losses of a predominantly coal fleet relative to natural gas competition in wholesale markets. A more textbook implementation of deregulation would have privatised those losses and shielded customers as a result.

The above implementation failures are illuminated by the data for the Cincinnati metro area (Duke Energy). Duke Energy is the only utility in the state that pursued functional divestiture. It is the only metro area in the state that observed a reversal of the pre-retail restructuring price trend and substantial welfare gains. Unlike the other utilities in the state, Duke Energy did not have an ageing coal fleet indirectly on their balance sheets and, therefore, no instrumental incentive to socialise private losses.

Although many prior studies have approached this issue with more breadth, such as national or multistate studies, we approached this issue with greater depth by digging deeper into the dynamics of a major deregulated state. We believe that the issues identified in this article highlight important aspects of restructuring, and policy implementation more broadly, that should inform many other states and nations. We thus maintain that, in most states, simply declaring a state "regulated" or "deregulated" is too simplistic, devoid of fundamental institutional dynamics. Rather, we suggest that restructuring exists on a continuum of degrees of commission intervention. Ohio does not have completely deregulated retail markets according to theoretical definitions, but it does reflect vestiges of commission control and utility intervention that are present in many peer states.

States such as Ohio have two choices in addressing flaws associated with restructuring; movement towards reregulation, or greater market-basis pricing with 
less commission intervention. Although the former would represent a near reversal of current policy towards an established outcome, the latter represents policy adjustment towards a less clear path forward. Thus, although we feel that we have informed the overall question of whether markets make good commissioners, we reflect on the perhaps equally important question of whether commissioners make good markets.

Acknowledgements. The authors thank the Battelle Center for Science and Technology Policy at the John Glenn College of Public Affairs for its generous support. The authors are grateful to Asma Diallo for valuable research assistance. The following individuals and organisations are also recognised for important comments and support in this work: William Michael, Edward Hill, Dorothy Bremer, Pat Frase and the PUCO. Any errors or omissions are solely those of the authors.

\section{References}

Abadie A and Gardeazabal J (1999) The Economic Costs of Conflict: A Case Study of the Basque Country. The American Economic Review 93(1): 113-132.

Appelbaum E and Katz E (1987) Seeking Rents by Setting Rents: The Political Economy of Rent Seeking. The Economic Journal 97(387): 685-699.

Apt J (2005) Competition Has Not Lowered US Industrial Electricity Prices. The Electricity Journal 18(2): 52-61.

Baillie RT (1996) Long Memory Processes and Fractionally Integrated in Econometrics. Journal of Econometrics 73(1): 5-59.

Blumsack S, Lave L and Apt J (2008) Electricity Prices and Costs Under Regulation and Restructuring. Presented at 2008 Industry Studies Conference, Boston.

Borenstein S and Bushnell JB (2015) The U.S. Electricity Industry after 20 Years of Restructuring. Annual Review of Economics 7(1): 437-463.

Box GEP and Jenkins GM (1970) Time Series Analysis, Forecasting and Control, 1st ed. San Francisco, CA: Holden-Day.

Box-Steffensmeier JM and Smith RM (1998) Investigating Political Dynamics Using Fractional Integration Methods. American Journal of Political Science 42(2): 661-689.

Box-Steffensmeier JM, Freeman JR, Hitt MP and Pevehouse JCW (2014) Time Series Analysis for the Social Sciences. Cambridge: Cambridge University Press.

Brennan TJ (2007) Consumer Preference Not to Choose: Methodological and Policy Implications. Energy Policy 35(3): 1616-1627.

Bushnell JB and Wolfram C (2005) Ownership Change, Incentives and Plant Efficiency: The Divestiture of US Electric Generation Plants. Berkeley, CA: Center for the Study of Energy Markets.

Campbell DT and Stanley J (1963) Experimental and Quasi-Experimental Designs for Research, 1st ed. Chicago, IL: Wadsworth Publishing.

Chandley JD (2001) A Standard Market Design for Regional Transmission Organizations. The Electricity Journal 14(10): 27-53.

Chapman D, Vossler CA, Mount TD, Barboni V, Thomas RJ and Zimmerman RD (2004) Market Efficiency, Competition, and Communication in Electric Power Markets: Experimental Results. Ecological Economics 48(3): 317-327.

Carter DP, Weible CM, Siddiki SN, Brett J and Chonaiew SM (2015) Assessing Policy Divergence: How to Investigate the Differences Between a Law and a Corresponding Regulation. Public Administration 93 (1): 159-176.

Cicala S (2014) When Does Regulation Distort Costs? Lessons from Fuel Procurement in US Electricity Generation (No. w20109). Cambridge, MA: National Bureau of Economic Research.

Craig JD and Savage SJ (2013) Market Restructuring, Competition and the Efficiency of Electricity Generation: Plant-level Evidence from the United States 1996 to 2006. The Energy Journal 34(1): 1-31.

Davis LW and Wolfram C (2012) Deregulation, Consolidation, and Efficiency: Evidence from US Nuclear Power. American Economic Journal: Applied Economics 4(4): 194-225.

Dias JG and Ramos SB (2014) Heterogeneous Price Dynamics in US Regional Electricity Markets. Energy Economics 46, 453-463. 
Dickey DA and Fuller WA (1974) Distribution of the Estimators for Autoregressive Time Series with A Unit Root. Journal of the American Statistical Association 74(366): 427-431.

Det Norske Veritas - Germanischer Lloyd (DNV-GL) (2015) U.S. Competitive Retail Power \& Gas Markets [Map], https://www.dnvgl.com/energy/brochures/download/retail-energy-choice-by-state.html (accessed 1 December 2016).

Energy Information Administration (EIA) (2001) State Electricity Profiles - Ohio. http://www.eia.gov/ electricity/state/archive/062999.pdf (accessed 1 December 2016).

Electricity Information Administration (EIA) (2012). Electric Sales, Revenue and Average Price. Table 5A. Residential Average Monthly Bill by Census Division and State. https://www.eia.gov/electricity/ sales_revenue_price/ (accessed 1 December 2016).

Enders W (2014) Applied Econometric Time Series, 1st ed. New York, NY: John Wiley \& Sons.

Esterling KM (2009) The Political Economy of Expertise: Information and Efficiency in American National Politics. Ann Arbor, MI: University of Michigan Press.

Eto JH, Hale DR and Lesieutre BC (2006) Toward More Comprehensive Assessments of FERC Electricity Restructuring Policies: A Review of Recent Benefit-cost Studies of RTOs. The Electricity Journal 19(10): 50-62.

Fagan ML (2006) Measuring and Explaining Electricity Price Changes in Restructured States. The Electricity Journal 19(5): 35-42.

Gamble A, Juliusson EA and Gärling T (2009) Consumer Attitudes Towards Switching Supplier in Three Deregulated Markets. The Journal of Socio-Economics 38(5): 814-819.

Giulietti M, Price CW and Waterson M (2005) Consumer Choice and Competition Policy: A Study of UK Energy Markets. The Economic Journal 115(506): 949-968.

Green RJ and Newbery DM (1992) Competition in the British Electricity Spot Market. Journal of Political Economy 100(5): 929-953.

Hamilton JD (1994) Time Series Analysis, 1st ed. Princeton, NJ: Princeton University Press.

Hill HC (2003) Understanding Implementation: Street-Level Bureaucrats' Resources for Reform. Journal of Public Administration Research and Theory 13(3): 265-282.

Hilke JC (2008) Economics, Competition, and Costs in the Restructuring of US Electricity Markets. Review of Industrial Organization 32(3-4): 289-296.

Hogan WW (1998) Independent System Operator: Pricing and Flexibility in A Competitive Electricity Market. Center for Business and Government, JF Kennedy School of Government, Harvard University, https://www.hks.harvard.edu/FS/whogan/iso98.pdf (accessed 1 December 2016).

Hortaçsu A and Puller SL (2008) Understanding Strategic Bidding in Multi-unit Auctions: A Case Study of the Texas Electricity Spot Market. The RAND Journal of Economics 39(1): 86-114.

Hortaçsu A, Madanizadeh SA and Puller SL (2017) Power to Choose? An Analysis of Consumer Inertia in the Residential Electricity Market. American Economic Journal: Economic Policy 9(4): 192-226.

Huber JD and Shipan CR (2002) Deliberate Discretion? The Institutional Foundations of Bureaucratic Autonomy. New York: Cambridge University Press.

Hunt S (2002) Making Competition Work in Electricity. Volume 146. Hoboken, NJ: John Wiley \& Sons.

Joskow PL (2008) Lessons Learned from Electricity Market Liberalization. The Energy Journal 29(2): 9-42.

Joskow PL (2006) Markets for Power in the United States: An Interim Assessment. The Energy Journal 27 (1): $1-36$.

Joskow PL (2005a) The Difficult Transition to Competitive Electricity Markets in the United States. In Griffin M. and Puller S. L. (eds.), Electricity Deregulation: Choices and Challenges, 1st ed. Chicago, IL: University of Chicago Press, 31-97.

Joskow PL (2005b) Transmission Policy in the United States. Utilities Policy 13(2): 95-115.

Joskow PL and Schmalensee R (1983) Markets for Power: An Analysis of Electric Utility Deregulation. Cambridge, MA: MIT Press.

Krueger AO (1974) The Political Economy of the Rent-Seeking Society. The American Economic Review 64(3): 291-303.

Kwoka J (2008) Restructuring the US Electric Power Sector: A Review of Recent Studies. Review of Industrial Organization 32(3-4): 165-196.

Littlechild S (2008) Municipal Aggregation and Retail Competition in the Ohio Energy Sector. Journal of Regulatory Economics 34(2): 164-194. 
Lo AW and MacKinlay AC (1988) Stock Market Prices Do Not Follow Random Walks: Evidence from A Simple Specification Test. Review of Financial Studies 1(1): 41-66.

Mansur ET (2008) Measuring Welfare in Restructured Electricity Markets. The Review of Economics and Statistics 90(2): 369-386.

Mahoney J and Thelen K (2010) A Theory of Gradual Institutional Change. In Mahoney J and Thelen K (eds.), Explaining Institutional Change: Ambiguity, Agency, and Power. Cambridge: Cambridge University Press, $1-37$.

Markiewicz K, Rose NL and Wolfram C (2004) Do Markets Reduce Costs? Assessing the Impact of Regulatory Restructuring on US Electric Generation Efficiency (No. w11001). Cambridge, MA: National Bureau of Economic Research.

Mazmanian DA and Sabatier PA (1981) Effective Policy Implementation, 1st ed. Florence, MA: Free Press.

National Association of Regulatory Utility Commissioners (NARUC) (2013) History of Electric Regulation in Ohio [PowerPoint Slides], http://pubs.naruc.org/pub/53924A2F-2354-D714-51526C4088474A4A (accessed 1 December 2016).

Newbery DM (1999) Privatization, Restructuring, and Regulation of Network Utilities. The Walras-Pareto Lectures Cambridge: MIT Press.

Ohio Legislative Service Commission (OLSC) (1999) Final Analysis, Am. Sub. S.B. 3. Columbus, OH, http://www.lsc.ohio.gov/analyses/99-sb3.pdf (accessed 1 December 2016).

Ohio Legislative Service Commission (OLSC) (2008) Final Analysis, Am. Sub. S.B. 221. Columbus, OH, http://www.lsc.ohio.gov/analyses127/08-sb221-127.pdf (accessed 1 December 2016).

Peltzman S (1989) The Economic Theory of Regulation after A Decade of Deregulation. Brookings Papers on Economic Activity: Microeconomics, 1-41.

Phillips CF (1993) The Regulation of Public Utilities: Theory and Practice. Public Utilities Reports. Arlington, VI.

Pollitt MG (2012) Lessons from the History of Independent System Operators in the Energy Sector. Energy Policy 47, 32-48.

Price CW (2005) The Effect of Liberalizing UK Retail Energy Markets on Consumers. Oxford Review of Economic Policy 21(1): 128-144.

Public Utilities Commission of Ohio (PUCO) (2016a) Electric Customer Choice Switch Rates and Aggregation Activity, http://www.puco.ohio.gov/puco/index.cfm/industry-information/statistical-reports/ electric-customer-choice-switch-rates-and-aggregation-activity/\#sthash.hPzkQzUI.dpbs (accessed 1 December 2016).

Public Utilities Commission of Ohio (PUCO) (2016b) FirstEnergy's Electric Security Plan, http://www. puco.ohio.gov/puco/index.cfm/be-informed/consumer-topics/firstenergy-s-electric-security-plan/\#sthas h.vIpUoBG7.dpbs (accessed 1 December 2016).

Public Utilities Commission of Ohio (PUCO) (2012) Case Number 12-3151-EL-COI, Entry Order from PUCO, Entry 127, http://dis.puc.state.oh.us/TiffToPDf/A1001001A14A16A95144H29544.pdf (accessed 1 December 2016).

Public Utilities Commission of Ohio (PUCO) (2007) Electric Rate Stabilization Plans: Ensuring Rate Certainty in Ohio, http://www.getpurenergy.com/states/forms/Electric\%20Rate\%20Stabilization.pdf (accessed 1 December 2016).

Puller SL (2007) Pricing and Firm Conduct in California's Deregulated Electricity Market. The Review of Economics and Statistics 89(1): 75-87.

Radaelli C (1995) The Role of Knowledge in the Policy Process. Journal of European Public Policy 2(2): $159-183$.

Radaelli C (2004) The Puzzle of Regulatory Competition. Journal of Public Policy 24(1): 1-23.

Ros AJ (2017) An Econometric Assessment of Electricity Demand in the United States Using Utilityspecific Panel Data and the Impact of Retail Competition on Prices. The Energy Journal 38(4): 73-99.

Sabatier P and Mazmanian D (1980) The Implementation of Public Policy: A Framework of Analysis. Policy Studies Journal 8(4): 538-560.

Shadish WR, Cook TD and Campbell DT (2002) Experimental and Quasi-Experimental Designs for Generalized Causal Inference. Wadsworth: Cengage Learning.

Shapiro SA and Tomain JP (2003) Regulatory Law and Policy: Cases and Materials, 3rd ed. New York, NY: Lexis Nexis. 
Sowell F (1992) Modeling Long-run Behavior with the Fractional ARIMA Model. Journal of Monetary Economics 29(2): 277-302.

Stigler GJ and Friedland C (1962) What Can Regulators Regulate-the Case of Electricity. Journal of Law \& Economics 5, 1-16.

Su X (2015) Have Customers Benefited from Electricity Retail Competition? Journal of Regulatory Economics 47, 146-182.

Swadley A and Yücel M (2011) Did Residential Electricity Rates Fall After Retail Competition? A Dynamic Panel Analysis. Energy Policy 39(12): 7702-7711.

Taber J, Chapman D and Mount T (2006) Examining the Effects of Deregulation on Retail Electricity Prices. Department of Applied Economics and Management, Working Paper 2005-14, Cornell University. http://publications.dyson.cornell.edu/research/researchpdf/wp/2005/Cornell_Dyson_wp0514.pdf (accessed 1 December 2016).

Tullock G (2001) Efficient Rent Seeking. In Lockard A. A. and Tullock G. (eds.), Efficient Rent-Seeking. Boston, MA: Springer, 3-16.

Winston C (1993) Economic Deregulation: Days of Reckoning for Microeconomists. Journal of Economic Literature 31(3): 1263-1289.

Wright CL (1977) A Note on the Decision Rules of Public Regulatory Agencies. Public Choice 31(1): 151-155.

Yang Y (2014) Understanding Household Switching Behavior in the Retail Electricity Market. Energy Policy 69, 406-414.

Zahariadis N and Exadaktylos T (2016) Policies That Succeed and Programs That Fail: Ambiguity, Conflict, and Crisis in Greek Higher Education. Policy Studies Journal 44(1): 59-82. 


\section{Appendix}

Table A.1, Table A.2, Table A.3, Table A.4, Table A.5, Table A.6.

Table A.1. Key market events in the history of Ohio's four major investor-owned utilities

\begin{tabular}{|c|c|c|c|c|}
\hline & AEP Ohio & FirstEnergy & DP\&L & Duke \\
\hline Market development period ends & $12 / 31 / 2005$ & $12 / 31 / 2005$ & $12 / 31 / 2005$ & $12 / 31 / 2005$ \\
\hline Rate stabilization period ends & $12 / 31 / 2008$ & $12 / 31 / 2008$ & $12 / 31 / 2010$ & $12 / 31 / 2008$ \\
\hline First MRO/ESP proposal & $7 / 31 / 2008$ & $7 / 31 / 2008$ & $10 / 10 / 2008$ & $7 / 31 / 2008$ \\
\hline First MRO/ESP approved by PUCO & $3 / 18 / 2009$ & $3 / 4 / 2009$ & $6 / 24 / 2009$ & $12 / 17 / 2008$ \\
\hline Second MRO/ESP proposal & $1 / 27 / 2011$ & $3 / 23 / 2010$ & $10 / 5 / 2012$ & $11 / 15 / 2010$ \\
\hline $\begin{array}{l}\text { Second MRO/ESP proposal approved } \\
\text { by PUCO }\end{array}$ & $11 / 13 / 2013$ & $8 / 25 / 2010$ & $9 / 4 / 2013$ & $11 / 22 / 2011$ \\
\hline Third MRO/ESP proposal & $12 / 20 / 2013$ & 4/13/2012 & N/A & $5 / 29 / 2014$ \\
\hline $\begin{array}{l}\text { Third MRO/ESP proposal approved } \\
\text { by PUCO }\end{array}$ & $2 / 25 / 2015$ & $1 / 30 / 2013$ & N/A & $4 / 2 / 2015$ \\
\hline First competitive auction date & 2/25/2014 & $5 / 13 / 2009$ & $10 / 28 / 2013$ & $12 / 14 / 2011$ \\
\hline $\begin{array}{l}\text { First auction component enters } \\
\text { into effect }\end{array}$ & $4 / 1 / 2014$ & $6 / 1 / 2009$ & $1 / 1 / 2014$ & $1 / 1 / 2012$ \\
\hline
\end{tabular}

Note: $\mathrm{AEP}=$ American Electric Power; $\mathrm{DP} \& \mathrm{~L}=$ Dayton Power \& Light; MRO = Market Rate Offer; ESP = Electric Security Plan; PUCO = Public Utilities Commission of Ohio. 
Table A.2. Number and proportion of residential customers facing standard service offer rates by each utility and major city

\begin{tabular}{|c|c|c|c|c|c|c|c|c|c|c|}
\hline \multirow[b]{2}{*}{ Date } & \multirow{2}{*}{$\begin{array}{l}\text { FirstEnergy } \\
\text { (Akron) } \\
\text { Sso Customers }\end{array}$} & \multirow{2}{*}{$\begin{array}{c}\text { AEP } \\
\text { (Canton) } \\
\text { \% Switched }\end{array}$} & \multirow{2}{*}{$\begin{array}{l}\text { Duke Energy } \\
\text { (Cincinnati) } \\
\text { SSO Customers }\end{array}$} & \multirow{2}{*}{$\begin{array}{l}\text { FirstEnergy } \\
\text { (Cleveland) } \\
\text { \% Switched }\end{array}$} & \multicolumn{2}{|c|}{ AEP (Columbus) } & \multicolumn{2}{|c|}{ DP\&L (Dayton) } & \multicolumn{2}{|c|}{ FirstEnergy (Toledo) } \\
\hline & & & & & $\begin{array}{c}\text { SSO } \\
\text { Customers }\end{array}$ & $\begin{array}{c}\% \\
\text { Switched }\end{array}$ & $\begin{array}{c}\text { SSO } \\
\text { Customers }\end{array}$ & $\begin{array}{c}\% \\
\text { Switched }\end{array}$ & $\begin{array}{c}\text { SSO } \\
\text { Customers }\end{array}$ & $\begin{array}{c}\% \\
\text { Switched }\end{array}$ \\
\hline 2009 & 582,482 & 37.4 & 582,488 & 0.0 & 635,997 & 0.0 & 456,144 & 0.0 & 132,910 & 51.7 \\
\hline 2010 & 351,458 & 60.2 & 575,964 & 0.0 & 633,765 & 0.0 & 454,304 & 0.0 & 98,479 & 61.3 \\
\hline 2011 & 329,680 & 64.1 & 586,328 & 3.1 & 639,541 & 4.4 & 411,122 & 9.6 & 101,073 & 62.9 \\
\hline 2012 & 283,740 & 69.1 & $1,012,682$ & 20.4 & - & - & 329,884 & 27.4 & 81,490 & 70.0 \\
\hline 2013 & 253,945 & 72.4 & 928,838 & 27.2 & - & - & 272,154 & 40.3 & 71,140 & 73.8 \\
\hline 2014 & 276,392 & 70.0 & 887,667 & 30.5 & - & - & 250,967 & 45.0 & 80,284 & 70.3 \\
\hline 2015 & 300,004 & 67.5 & 860,355 & 32.8 & - & - & 254,273 & 44.4 & 89,582 & 66.9 \\
\hline
\end{tabular}

Notes: AEP = American Electric Power; DP\&L = Dayton Power \& Light; SSO = standard service offer; PUCO = Public Utilities Commission of Ohio.

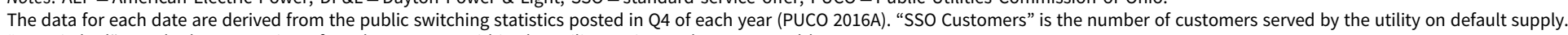
"\% Switched" equals the proportion of total customers within the Utility territory who are served by a CRES. 
Table A.3. Dickey-Fuller tests

\begin{tabular}{ll}
\hline & Test Statistic \\
\hline Akron & $-3.964^{\star \star}$ \\
Canton & -3.139 \\
Cincinnati & -2.136 \\
Cleveland & $-5.494^{\star \star \star}$ \\
Columbus & -2.769 \\
Dayton & -2.142 \\
Toledo & $-5.853^{\star \star \star}$ \\
\hline
\end{tabular}

Note: ${ }^{\star \star \star} \mathrm{p}<0.01,{ }^{\star \star} \mathrm{p}<0.05$.

Table A.4. Variance ratio tests on electricity prices

\begin{tabular}{lllll}
\hline & \multicolumn{3}{c}{$\operatorname{VR}(k)$} \\
\cline { 2 - 5 } & \multicolumn{1}{c}{$\operatorname{VR}(2)$} & $\operatorname{VR}(4)$ & $\operatorname{VR}(8)$ & $\operatorname{VR}(16)$ \\
\hline Akron & 0.929 & 0.820 & $0.491^{\star}$ & $0.321^{\star}$ \\
Canton & $0.756^{\star \star \star}$ & $0.657^{\star \star}$ & $0.512^{\star}$ & 0.382 \\
Cincinnati & 0.932 & 0.929 & 0.774 & 0.741 \\
Cleveland & 0.959 & 0.831 & $0.448^{\star \star}$ & $0.306^{\star}$ \\
Columbus & 0.858 & 0.872 & 0.794 & 0.515 \\
Dayton & $0.794^{\star \star}$ & $0.644^{\star \star}$ & $0.506^{\star}$ & 0.589 \\
Toledo & $0.807^{\star \star}$ & $0.624^{\star \star}$ & $0.342^{\star \star}$ & $0.235^{\star \star}$ \\
\hline
\end{tabular}

Note: ${ }^{\star * *} \mathrm{p}<0.01,{ }^{* \star} \mathrm{p}<0.05,{ }^{*} \mathrm{p}<0.1$.

Table A.5. Reset results for nonlinearity

\begin{tabular}{lcc}
\hline & F-Test & p-Value \\
\hline Akron & 1.01 & 0.3669 \\
Canton & 0.49 & 0.6154 \\
Cincinnati & 0.54 & 0.6576 \\
Cleveland & 1.12 & 0.3295 \\
Columbus & 0.95 & 0.4171 \\
Dayton & 1.81 & 0.1671 \\
Toledo & 0.95 & 0.3906 \\
\hline
\end{tabular}

Table A.6. Portmanteau and Bartlett's white noise tests of residuals

\begin{tabular}{|c|c|c|c|c|c|c|}
\hline \multirow{3}{*}{ Akron } & \multicolumn{2}{|c|}{ Pre-Restructuring } & \multicolumn{2}{|c|}{ Post-Restructuring } & \multicolumn{2}{|c|}{ Full Series } \\
\hline & $Q=33.99$ & $p=0.20$ & $Q=25.83$ & $p=0.96$ & $Q=40.60$ & $p=0.44$ \\
\hline & $B=1.08$ & $p=0.19$ & $B=0.53$ & $p=0.94$ & $B=0.65$ & $p=0.79$ \\
\hline \multirow[t]{2}{*}{ Canton } & $Q=30.07$ & $p=0.36$ & $Q=25.59$ & $p=0.97$ & $Q=33.85$ & $p=0.74$ \\
\hline & $B=1.37$ & $p=0.05$ & $B=0.78$ & $p=0.57$ & $B=0.99$ & $p=0.29$ \\
\hline \multirow[t]{2}{*}{ Cincinnati } & $Q=22.02$ & $p=0.78$ & $Q=35.55$ & $p=0.67$ & $Q=41.97$ & $p=0.39$ \\
\hline & $B=0.40$ & $p=0.99$ & $B=0.55$ & $p=0.92$ & $B=0.56$ & $p=0.91$ \\
\hline \multirow[t]{2}{*}{ Cleveland } & $Q=24.55$ & $p=0.65$ & $Q=53.82$ & $p=0.07$ & $Q=45.07$ & $p=0.27$ \\
\hline & $B=0.59$ & $p=0.88$ & $B=0.72$ & $p=0.67$ & $B=0.60$ & $p=0.87$ \\
\hline \multirow[t]{2}{*}{ Columbus } & $Q=34.03$ & $p=0.20$ & $Q=31.92$ & $p=0.82$ & $Q=39.97$ & $p=0.47$ \\
\hline & $B=0.85$ & $p=0.46$ & $B=0.63$ & $p=0.82$ & $B=0.67$ & $p=0.75$ \\
\hline \multirow[t]{2}{*}{ Dayton } & $Q=33.72$ & $p=0.75$ & $Q=21.89$ & $p=0.79$ & $Q=29.48$ & $p=0.89$ \\
\hline & $B=1.05$ & $p=0.22$ & $B=0.55$ & $p=0.92$ & $B=0.93$ & $p=0.35$ \\
\hline \multirow[t]{2}{*}{ Toledo } & $Q=25.62$ & $p=0.59$ & $Q=40.11$ & $p=0.47$ & $Q=43.74$ & $p=0.32$ \\
\hline & $B=0.60$ & $\mathrm{p}=0.86$ & $B=0.95$ & $p=0.33$ & $B=0.82$ & $\mathrm{p}=0.51$ \\
\hline
\end{tabular}


Noah Dormady et al.
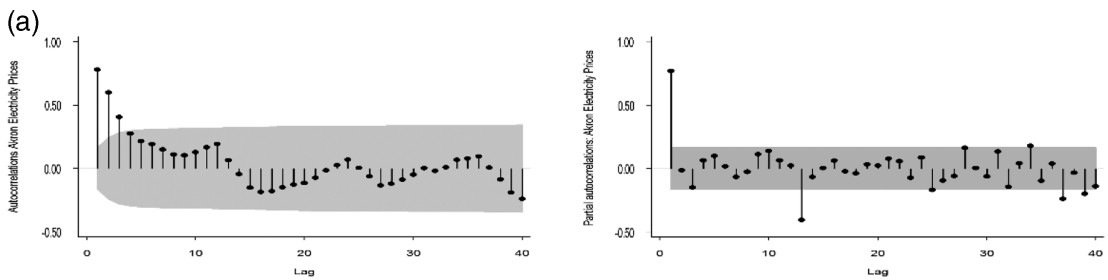

(b)
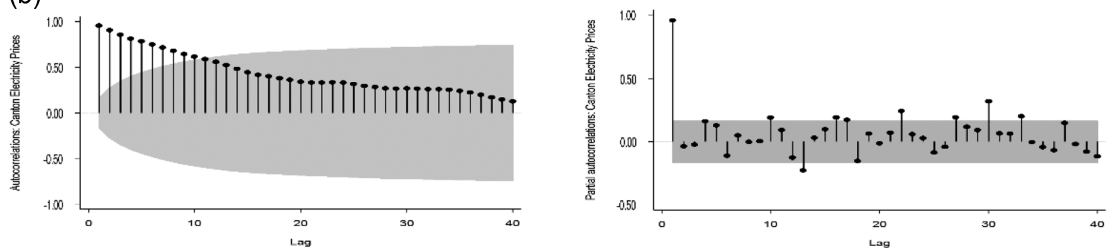

(c)
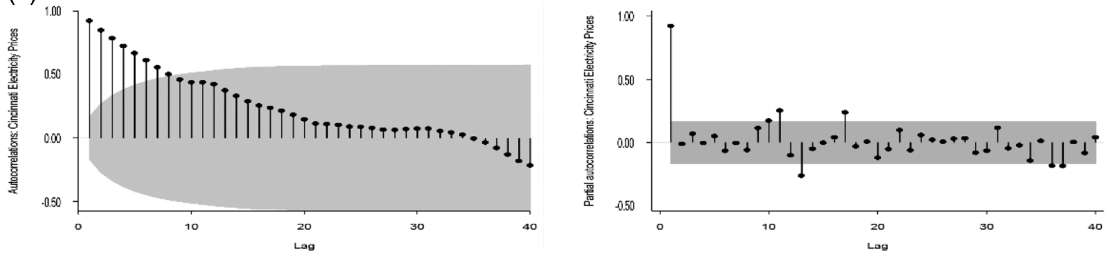

(d)
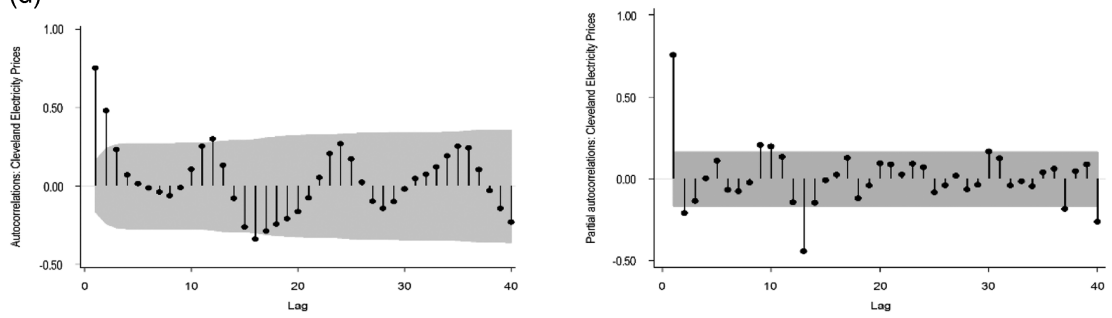

(e)
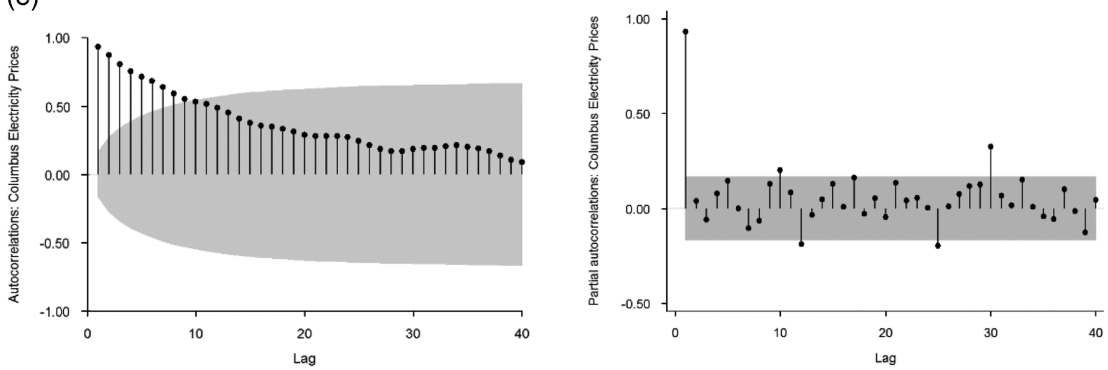

Figure A.1. Correlograms of electricity prices. (a) Akron, (b) Canton, (c) Cincinnati, (d) Cleveland, (e) Columbus, (f) Dayton and (g) Toledo 

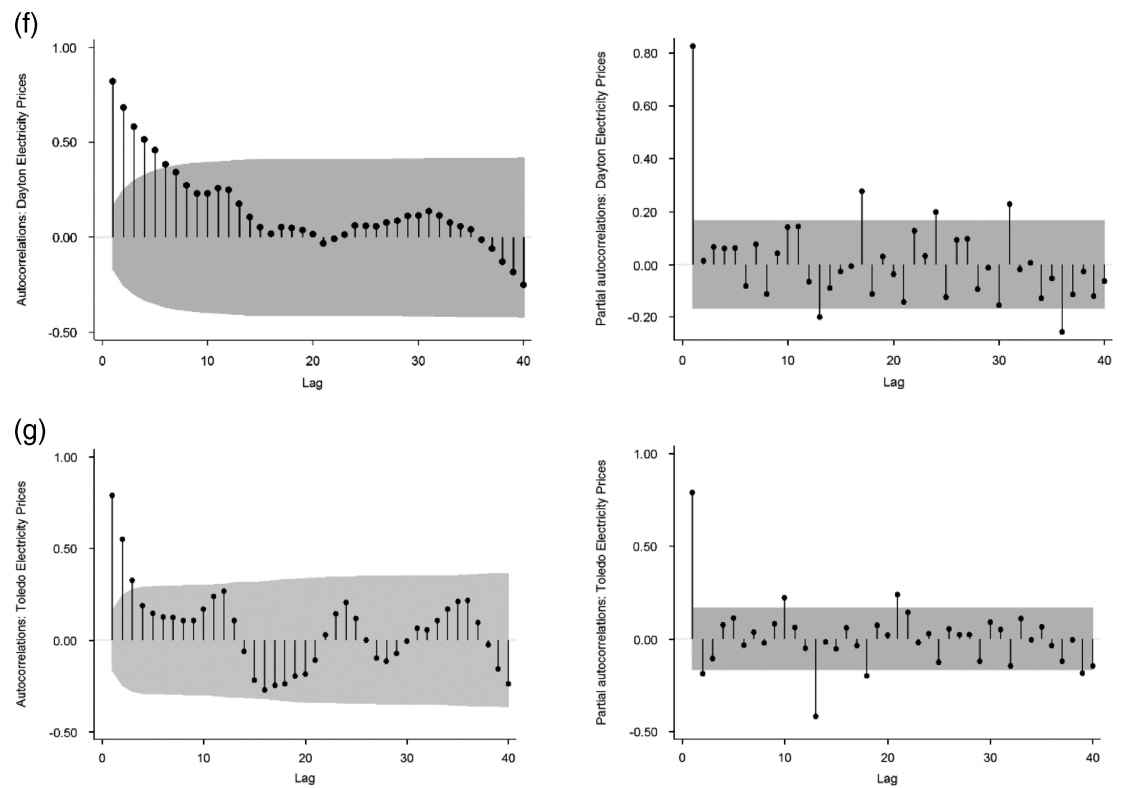

Figure A.1. Continued.

Cite this article: Dormady N., Jiang Z., Hoyt M. 2019. Do markets make good commissioners?: A quasiexperimental analysis of retail electric restructuring in Ohio. Journal of Public Policy 39: 483-515, doi: $10.1017 / \mathrm{S} 0143814 \mathrm{X} 18000168$ 